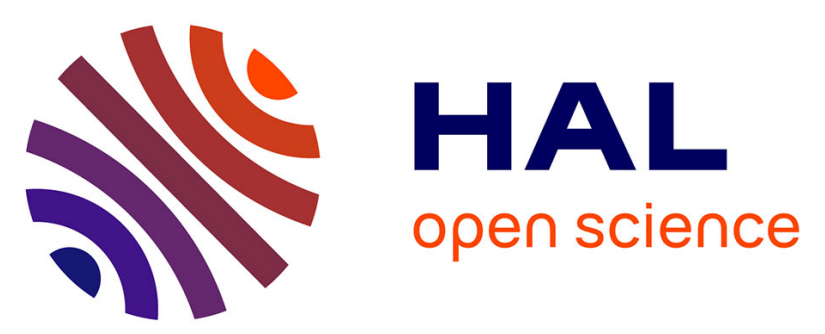

\title{
Effects of strain rate on the characteristics of PLC deformation bands for AA5083-H116 aluminium alloy
}

A. Benallal, Torod Berstad, Tore Borvik, Odd Sture Hopperstad, Rodrigo

Nogueira de Codes

\section{- To cite this version:}

A. Benallal, Torod Berstad, Tore Borvik, Odd Sture Hopperstad, Rodrigo Nogueira de Codes. Effects of strain rate on the characteristics of PLC deformation bands for AA5083-H116 aluminium alloy. Philosophical Magazine, 2009, 88 (28-29), pp.3311-3338. 10.1080/14786430802468223 . hal00513974

\section{HAL Id: hal-00513974 \\ https://hal.science/hal-00513974}

Submitted on 1 Sep 2010

HAL is a multi-disciplinary open access archive for the deposit and dissemination of scientific research documents, whether they are published or not. The documents may come from teaching and research institutions in France or abroad, or from public or private research centers.
L'archive ouverte pluridisciplinaire HAL, est destinée au dépôt et à la diffusion de documents scientifiques de niveau recherche, publiés ou non, émanant des établissements d'enseignement et de recherche français ou étrangers, des laboratoires publics ou privés. 


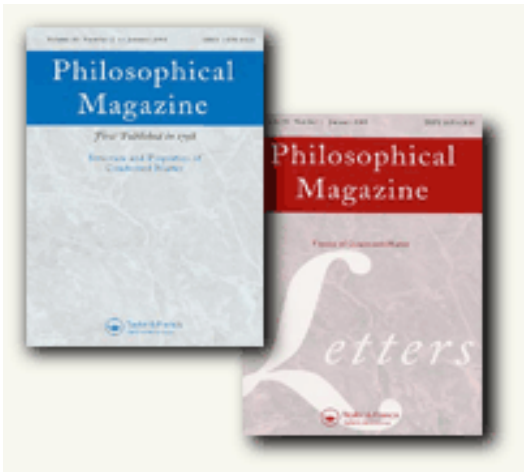

\section{Effects of strain rate on the characteristics of PLC deformation bands for AA5083-H116 aluminium alloy}

\begin{tabular}{|c|c|}
\hline Journal: & $\begin{array}{l}\text { Philosophical Magazine \& Philosophical Magazine } \\
\text { Letters }\end{array}$ \\
\hline Manuscript ID: & TPHM-08-Feb-0033.R2 \\
\hline Journal Selection: & Philosophical Magazine \\
\hline $\begin{array}{l}\text { Date Submitted by } \\
\text { the Author: }\end{array}$ & 27-Jun-2008 \\
\hline $\begin{array}{r}\text { Complete List of } \\
\text { Authors: }\end{array}$ & $\begin{array}{l}\text { Benallal, A.; ENS de Cachan, Laboratoire de } \\
\text { Mecanique et Technologie } \\
\text { Berstad, Torod; SINTEF Materials and Chemistry, } \\
\text { Applied Mechanics and Corrosion } \\
\text { Borvik, Tore; NTNU, Structural Impact Laboratory } \\
\text { (SIMLab), Centre for Research-based Innovation } \\
\text { (CRI) } \\
\text { Hopperstad, Odd Sture; NTNU, Structural Impact } \\
\text { Laboratory (SIMLab), Centre for Research-based } \\
\text { Innovation (CRI) } \\
\text { Nogueira de Codes, Rodrigo; ENS de Cachan, } \\
\text { Laboratoire de Mecanique et Technologie }\end{array}$ \\
\hline Keywords: & ageing, finite-element modelling \\
\hline $\begin{array}{r}\text { Keywords (user } \\
\text { supplied): }\end{array}$ & $\begin{array}{l}\text { Portevin-Le Chatelier effect, Digital infrared } \\
\text { thermography, Negative strain-rate sensitivity }\end{array}$ \\
\hline
\end{tabular}




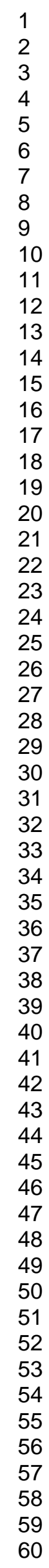

5) ScholaroNE"

http://mc.manuscriptcentral.com/pm-pml 


\title{
Effects of strain rate on the characteristics of PLC deformation bands for AA5083-H116 aluminium alloy
}

\author{
A. BENALLAL ${ }^{l *}$, T. BERSTAD ${ }^{2}$, T. BØRVIK ${ }^{3}$, O.S. HOPPERSTAD ${ }^{3}$, R. NOGUEIRA DE CODES ${ }^{l}$ \\ ${ }^{1}$ LMT-ENS Cachan/CNRS/Université Paris 6/ PRES UniverSud Paris, \\ 61 av. du Président Wilson, F-94235 Cachan, France \\ ${ }^{2}$ SINTEF Materials and Chemistry, Applied Mechanics and Corrosion, \\ NO-7465 Trondheim, Norway. \\ ${ }^{3}$ Structural Impact Laboratory - SIMLab, Centre for Research-based Innovation (CRI)/ \\ Department of Structural Engineering, NTNU, NO-7491 Trondheim, Norway
}

\begin{abstract}
An experimental, theoretical and numerical investigation of the Portevin-Le Chatelier (PLC) effect in the aluminium alloy AA5083-H116 is undertaken in this paper. Five different tests at different overall strain rates are carried out on smooth flat specimens in order to exhibit the effects of strain rate on the characteristics of the deformation bands and their propagation. Both digital image correlation and digital infrared thermography are used to capture and characterize the spatio-temporal features of the PLC behaviour. Inhomogeneous deformation with various localization bands caused by the PLC effect is observed in all the tests and the formation, evolution and propagation of these deformation bands are visualized allowing their characteristics to be measured. An elasto-viscoplastic constitutive model, developed for metals exhibiting dynamic strain ageing, is used to represent the material behaviour. Linear stability analysis with the adopted constitutive model is shown to give the orientations of the bands, but fails to predict the critical strain at which serrated
\end{abstract}

\footnotetext{
* Corresponding author. Tel.: + 331474027 39; fax: + 33147402240 .

E-mail address: Benallal@lmt.ens-cachan.fr (A. Benallal).
} 
yielding occurs. Finally, the model is used in 3D numerical simulations of the physical tests using explicit finite element analysis. The numerical results are compared with the experimental observations and the main deviations between tests and simulations are discussed.

Keywords: Portevin-Le Chatelier effect; Digital image correlation; Digital infrared thermography; Negative strain-rate sensitivity; Elasto-viscoplasticity; Non-linear finite element methods.

\section{Introduction}

AA5083-H116 aluminium alloy exhibits irregular plastic flow in a given range of strain rates and temperature [1]. In a uniaxial tension test for instance, this irregular flow results in inhomogeneous deformation with different types of localization bands. These bands can be static, hopping and sometimes propagating along the specimen. It is also observed in presence of this irregular flow that the material often fails by a shear localization mode prior to any diffuse necking in uniaxial tension and even under more complex states of stress [1][2].

This unstable plastic flow is understood as the consequences of solute-dislocation interaction at the microscopic level as suggested by Cottrel [3][4] and a full understanding of the micromechanical mechanisms and the relevant factors affecting the macroscopic behaviour of serrated plastic flow is still lacking. The reason for the serrations in the stress-strain curve is negative steady-state strain-rate sensitivity. The negative strain-rate dependence of the flow stress is attributed to dynamic strain ageing (DSA) associated with conditions when point defects can diffuse towards mobile dislocations and temporarily arrest them [5][6]. The results of DSA are higher flow stress and greater strain hardening at lower strain rates than for higher ones, and further serrated stress-strain curves, discontinuous plastic flow and propagating deformation bands during plastic straining. This phenomenon is also referred to as the Portevin-Le Chatelier (PLC) effect. DSA occurs for temperatures and strain rates within a certain range, and sometimes a critical strain level has to be reached for serrated yielding to take place [5]-[7]. An interesting historical presentation of the various studies of the PLC effect can be found in [8].

The PLC effect is a technologically important problem because it adversely affects the formability of the material. Inhomogeneous plastic straining increases the geometrical perturbations of the specimen, and thus reduces the strain to necking. Furthermore, the propagating deformation bands give rise to undesired markings on the surface of the shaped material [9][10]. In Clausen et al. [1], it was noted that shear failure only occurred in strain rate and temperature regimes inside the PLC domain, and it is therefore reasonable to 
assume that shear localization at least to some extent is due to DSA and the associated discontinuous plastic flow. This indicates that strain localization occurs due to the propagating bands, probably due to some kind of softening mechanism. Hopperstad et al. [11] showed in a numerical study that the PLC effects lead to a significant reduction in strain to necking both under uniaxial and biaxial tension. This type of information may be vital in e.g. metal forming operations.

The main objective of this paper is to analyze the effects of the overall strain rate on the PLC characteristics for AA5083-H116 aluminium alloy. These effects are first experimentally investigated and five tests are performed in the strain rate range $10^{-5} \mathrm{~s}^{-1}-10^{-1} \mathrm{~s}^{-1}$ using a smooth, flat specimen. A variety of new experimental techniques are now available that can be used for our purpose. The most common are the shadowgraph techniques [12], digital speckle pattern interferometry and digital speckle correlation [13][14], Digital Image Correlation (DIC) [15]-[19], multi-zone laser scanning extensometers [20], and infrared pyrometry [21]-[23]. Both DIC and Digital Infrared Thermography (DIT) techniques will be used in this work to detect and characterize spatio-temporal features of the PLC behaviour of the aluminium alloy AA5083H116. Next, we use linear stability analysis and an elasto-viscoplastic constitutive model including dynamic strain ageing to detect associated instabilities and extract some features of PLC deformation bands, mainly their orientations. Further, we underline the weaknesses of the model in reproducing other characteristics. Finally, three-dimensional nonlinear finite element simulations of the five tests are undertaken using the elasto-viscoplastic constitutive model including dynamic strain ageing. The effects of strain rate on the PLC characteristics obtained numerically are described and compared to the experimental data and the predictions of the linear perturbation approach.

\section{Experimental programme}

\subsection{Material}

The material studied in this investigation was the aluminium alloy AA5083-H116. The main alloying elements are magnesium with 4.4 weight percent, manganese with 0.7 weight percent and chromium with 0.15 weight percent. AA5083 may also contain minor quantities of elements such as iron, copper and zinc. It is important to notice that the amount of magnesium is higher than 3 weight percent, which is the maximum to be retained in solid solution at room temperature. This gives a potential instability leading to precipitation along grain boundaries or slip planes. Stress corrosion is thus a likely consequence in corrosive media. Special 
precautions have to be made during rolling in order to avoid this problem, and the temper H116 was therefore developed.

The AA5xxx series is well suited for rolling, and plates are thus an important product. The traditional use of such plates is naval structures such as ship hulls and offshore topsides, and the good corrosion resistance of the AA5xxx series gives further reasons for these marine applications.

\subsection{Specimen geometries and experimental procedures}

Five tests named T1, T2, T3, T4 and T5 in the sequel were carried out to observe and characterize the PLC bands in the process of deformation at different overall strain rates. All tests were carried out on the same specimen geometry which is depicted in Fig 1. It is a flat, smooth specimen with 2 mm thickness, 15 $\mathrm{mm}$ width and $120 \mathrm{~mm}$ gage length. The specimens were all cut from a $5 \mathrm{~mm}$ thick rolled plate and their axial

loading directions aligned with the rolling direction. The tests were carried out at room temperature in a servo-hydraulic material testing system (MTS model 810) with a $10 \mathrm{kN}$ load cell, in displacement control with clamp velocity adjusted to the desired strain rate in the range $10^{-5} \mathrm{~s}^{-1}-10^{-1} \mathrm{~s}^{-1}$. Note that all specimens were gripped and clamped at exactly the same gage length $(120 \mathrm{~mm})$ as shown in Fig 1.

Table 1 presents a brief summary of the tests with the chosen average strain rates. Both force and displacement data were recorded digitally at the frequency displayed in Table 2.

Two different techniques were used to observe and eventually characterize the PLC bands spatially and temporally, namely DIC and DIT. The gage length of the flat specimen was imaged with a fast CCD camera (model Ultima APX-RS) on one side and with an infrared camera (model JADE 570M) on the other side. The imaged zones for DIC and DIT are shown in Fig 1. Prior to the tests, one side of the specimen was decorated with finely sprayed black and white paints to enhance the image contrast and the other was sprayed with a fully black paint in order to enhance its emissivity.

For DIC the recorded digital images had either $128 \times 640$ or $128 \times 512$ pixels size (see Table 2 ). Images were recorded at a shutter speed of 50 or 125 frames per second. The principle of DIC is based on the fact that the distribution of grey scale values of a rectangular area in the initial image corresponds to the distribution of grey scale values of the same area in the destination image. A cumulative strain map can be obtained by comparing each current deformation image with the initial image while an incremental strain map can be computed by comparing the image at the current load step with the image recorded just before the current load increment. These maps are computed from the recorded data by the software Correli developed by Hild and co-workers [17]. The image sizes and acquisition speeds for DIT are also given in Table 2. 


\section{Experimental results}

\subsection{Stress-strain responses, failure modes and serrations characteristics}

Fig 2 shows the force-displacement responses for all the five tests up to failure, while Fig 3 displays the fractured specimens. Both figures show that some necking occurs for the three higher strain rates (T3, T4 and T5). It can also be seen that the final failure mode for all the tests is shear failure through the thickness of the specimen. More complex fracture surface was sometimes observed (two planes differently oriented). Fig 2 shows that serrations occur in all tests. The details of these serrations are given in Fig 4, where we present the load versus time curves for all the tests at two different stages of the deformation history: shortly after the PLC effect is noticeable and close to the end of the test. One observes in this last figure that these serrations only occur after a certain time. A closer look on the stress-strain behaviour shows that this corresponds to a strain threshold that varies from 0.005 to 0.02 when the strain rate is changed. The serrations are different at the two stages for tests T1, T2 and T3, while they do not seem to change significantly for tests T4 and T5. Note finally that the amplitudes of the serrations increase with strain and generally decrease when the applied overall strain rate increases. Fig 5 displays the evolution of the critical strain $\varepsilon_{c}$ corresponding to the occurrence of the PLC effect as a function of the strain rate. The critical strains were measured directly on the stress-strain curve but also through DIC and DIT. Note that for the lowest strain rate this information was only obtained from the stress-strain curve, while for the highest strain rate this was rather difficult and only measured values from DIC and DIT are provided. In Fig 5 one can also see the inverse behaviour of the critical strain, generally observed in the literature for aluminium alloys.

\subsection{Strain heterogeneity and band observations}

Fig 6 shows the strain-time histories for tests T2, T3 and T4 as measured by image correlation at the locations $\mathrm{X}$ and $\mathrm{Y}$ depicted in Fig 1. $\mathrm{X}$ is the centre of the specimen, while $\mathrm{Y}$ is located at a $20 \mathrm{~mm}$ distance from $\mathrm{X}$ in the direction where the loading is applied. The strains are measured by two "optical" strain gages located in the positions $X$ and $Y$ just mentioned. The size of these gages is $3.35 \mathrm{~mm} \times 3.35 \mathrm{~mm}$. The image correlation data was processed with the Corelli software [17] to obtain the corresponding strain history in these areas. Fig 7 shows the temperature histories for the five tests in the same locations $\mathrm{X}$ and $\mathrm{Y}$. Note that for test $\mathrm{T} 1$ carried out at the lowest strain rate only those zones where data were acquired are shown. The insert in the same figure shows a zoom of one of these zones displaying sharp peaks corresponding to the birth of static deformation bands. Both strain and temperature histories display the classical staircase behaviour where each stair is the manifestation of a band passing at these locations. This is the first evidence of the 
deformation bands and their evolution. These figures show that the strain carried by the bands increases with plastic deformation and therefore also the temperature increment increases.

DIC and DIT allow us to see more details of the nucleation and propagation of the bands. We present in the following these details for test T4 carried out at an average strain rate of $10^{-2} \mathrm{~s}^{-1}$. Fig 8 displays the whole test T4 and shows the temperature change $\Delta T(x=0, y, t)$ versus time along the vertical centerline of the specimen in the imaged area during the deformation process. The temperature change displayed in Fig 8 is obtained in the following way: at each acquisition time $t$, the acquired data is a matrix $T(x, y, t)$ representing the chart of temperatures as measured by the infrared camera, where $x$ represents lines (in the transverse direction) and $y$ columns (in the longitudinal direction corresponding to the tension axis), and ( $x, y)$ a pixel from the imaged zone in the specimen. To minimize noise in the visualization of the bands, the average temperature change over a line is considered

$$
\Delta T(x, y, t)=T(x, y, t+m \delta t)-\frac{1}{m} \sum_{j=0}^{j=m-1} T(x, y, t+j \delta t)
$$

where $\delta t$ is the acquisition shutter (in time between individual frames). The choice of the parameter $m$ depends on the cross head velocity and the acquisition speed during the test. For the tests carried out in this work, $m=50$ was used for T1, T2 and T3, $m=10$ was used for T4 and $m=1$ was used for T5.

The acquired thermal information clearly shows where and when bands nucleate and how they propagate. Fig 8 shows a number of these bands appearing, propagating and disappearing. Fig 8 (top) displays the temperature change versus time from the beginning of the test until the time $8.7 \mathrm{~s}$, before the specimen fractures. It shows that the first band nucleates at A and propagates until B where it stops. At this moment, another one emerges at $\mathrm{C}$ and propagates until D. A similar sequence follows in E-F, G-H and I-J. Other sequences (only slightly different from the first ones) are observed in K-L, M-N and O-P, then Q-R, S-T, U-V and W-X followed by Y-Z, A'-B', then C'-D', E'-F', then G'-H', I'-J' and finally K'-L', M'-N' and O'-P' where the band stops. Fig 8 (bottom) shows the end of the test up to failure. It is seen that as the last band eventually stops in P', the deformation localizes inside this band leading to final failure of the specimen. We also observe in Fig 8 that the speed of the bands decreases with strain (see the slope of the hot zones), and finally that the temperature inside the bands increases with strain.

Fig 9 shows the two-dimensional temperature change distributions over the imaged zone of the specimen in test T4 at four time locations $t=5.7 \mathrm{~s}, t=5.8 \mathrm{~s}, t=5.9 \mathrm{~s}$ and $t=6 \mathrm{~s}$. The time interval corresponds to 
segment E'-F' in Fig 8, and shows the propagation of the band. The orientation of the band is clearly seen in this figure. However, the width of the band seen in Fig 9 is not the real width. The real width $w_{b}$ is obtained by the simple correction

$$
w_{b}=\bar{w}_{b}-m v_{b} \delta t
$$

where $\bar{w}_{b}$ is the measured width in Fig 9 and $v_{b}$ is the speed of the band (measured as the slope in Fig 8). The temperature change over the specimen is better highlighted in Fig 10, giving a three-dimensional view of the bands shown in Fig 9. Similar results are obtained through image correlation analysis.

\subsection{Band velocities}

The band velocity is obtained from image correlation data, but also from infrared thermography. Indeed, if one refers to the strain and temperature histories shown in Fig 6 and Fig 7 as measured by the two optical strain gages and by the infrared camera, one just has to measure the time that a given band takes going from one gage to the other. This is also obtained by the slopes of the bands shown in Fig 8. The band velocities (measured in this last way) versus strain are presented in Fig 11 for all the tests. Numerical results (to be presented in section 5) are also displayed. It is seen from the figure that in all tests the band velocity decreases with straining, and that the band velocity roughly scales with the overall applied strain rate.

\subsection{Band orientations}

Band orientations can be obtained both from image correlation and infrared thermography. Here, they were obtained from results like those presented in Fig 9. Fig 12 shows the evolution of these orientations with straining for all tests and how they compare to the numerical simulations of section 5. Most measured angles lie between $55^{\circ}$ and $65^{\circ}$.

\subsection{Strain rates and temperature rates inside the bands}

The strain rates and temperature rates inside the bands can be measured from plots like those given in Fig 6 and Fig 7, and are given directly by the slopes of the stairs observed in these figures. Fig 13 shows the strain rate measured in this way as a function of strain. Fig 14 displays the temperature change in the band versus strain. The temperature change is measured in Fig 7 in terms of the variation of the temperature during the strain increase. The main observations are that the strain rate within the band is significantly higher than the 
applied overall strain rate, while the temperature within the bands increases with increasing strain and is in the order of $1^{\circ} \mathrm{C}$.

\subsection{Width of the bands}

The band widths are most readily obtained from pictures as those shown in Fig 9, but with the correction shown in Equation (2). The evolution of the width of the bands with strain for the different strain rates is displayed in Fig 15. It is seen that the data exhibit significant scatter, and it is difficult to make any clear conclusions with respect to the variation of the band width with strain and strain rate.

\section{Constitutive modelling and linear stability analysis}

\subsection{Elastic-viscoplastic constitutive equation with dynamic strain ageing}

An elasto-viscoplastic model for metals exhibiting dynamic strain ageing proposed by McCormick [6] is adopted. This model is similar to that used in FE simulations by Zhang et al. [24]. However, here the basic version described by Mesarovic [25] is taken as the starting point, since the model is intended for large-scale simulations of plastic forming for industrial applications. A detailed description of the constitutive equations, the stress-update algorithm and the parameter identification procedure is provided by Benallal et al. [2], and thus only the main equations are given below.

The von Mises equivalent stress $\sigma_{e q}$ is defined by

$$
\sigma_{e q}(\boldsymbol{\sigma})=\sigma_{Y}\left(t_{a}\right)+R(p)+\sigma_{v}(\dot{p})
$$

where $\boldsymbol{\sigma}$ is the Cauchy stress, $p$ is the equivalent plastic strain and $t_{a}$ is the average waiting time (used to describe dynamic strain ageing). The yield stress $\sigma_{Y}$ is given as

$$
\sigma_{Y}\left(t_{a}\right)=\sigma_{0}+S H\left(1-\exp \left\{-\left(\frac{t_{a}}{t_{d}}\right)^{\alpha}\right\}\right)
$$

where $\sigma_{0}$ is the yield stress for $t_{a}=0, S$ determines the instantaneous strain-rate sensitivity and $H, t_{d}$ and $\alpha$ are parameters governing dynamic strain ageing. The evolution of the average waiting time reads 


$$
d t_{a}=\left(1-\frac{t_{a}}{t_{a, s s}}\right) d t=d t-\frac{t_{a}}{\Omega} d p ; \quad t_{a, s s}=\frac{\Omega}{\dot{p}}
$$

where $\Omega$ is a material parameter and $t_{a, s s}$ is the steady-state value of the average waiting time. The strain hardening variable $R$ is defined as

$$
R(p)=\sum_{i=1}^{2} Q_{i}\left(1-\exp \left(-C_{i} p\right)\right)
$$

where $Q_{i}$ and $C_{i}$ are hardening parameters. The instantaneous rate dependence is described by the viscous stress $\sigma_{v}$ in the form

$$
\sigma_{v}(\dot{p})=S \ln \left\{1+\frac{\dot{p}}{\dot{p}_{0}}\right\}
$$

where $\dot{p}_{0}$ is a reference plastic strain rate.

Material characterization and parameter identification for AA5083-H116 alloy plates were presented in detail by Clausen et al. [1] and Benallal et al. [2], respectively. The model parameters were obtained based on tensile tests at a wide range of strain rates using an analytical approach, assuming constant plastic strain rate within the tensile tests. The resulting parameters from the fit are summarized in Table 3 and Table 4 . In addition, nominal values for aluminium were used for the density $\rho$, Young's modulus $E$ and Poisson's ratio $v$ as shown in Table 5 .

\subsection{Linear perturbation approach}

A linear perturbation approach is used to detect instabilities due to dynamic strain ageing and negative strain-rate sensitivity. The analysis is carried out assuming small strains, mainly to obtain critical strains at which the PLC effect emerges and the critical orientations of the associated deformation bands. Using a procedure similar to [26], perturbations in the form $\delta \mathbf{X}=\tilde{\mathbf{X}} e^{i \xi(\mathbf{n} \cdot \mathbf{x})+\eta t}$, where $\eta$ is related to the growth rate of the perturbation, $\xi$ is the mode wave number and $\mathbf{n}$ is a polarisation direction, which will play the role of the 
normal to the deformation band, are looked for to satisfy the linearized initial-boundary value problem. Such perturbation modes exist and eventually grow, when the following relation holds

$$
\operatorname{det}(\mathbf{n} \cdot \mathbf{H}(\bar{\eta}) \cdot \mathbf{n})=0
$$

where growth of perturbations is signalled by positive values of the real part of the eigenvalues $\bar{\eta}$. The modulus $\mathbf{H}(\bar{\eta})$ for the McCormick elasto-viscoplastic model takes the form

$$
\mathbf{H}(\bar{\eta})=\frac{\bar{\eta}}{1+\bar{\eta}} \mathbf{E}+\frac{K}{1+\bar{\eta}} \mathbf{1} \otimes \mathbf{1}-\frac{2 G\left\{\bar{\eta}-\frac{\tau(\bar{\eta})}{3 G}\right\}}{1+\frac{\tau(\bar{\eta})}{3 G}} \mathbf{N} \otimes \mathbf{N}
$$

where $\mathbf{E}$ is the elastic moduli, $K$ and $G$ are the bulk and shear moduli, and $\mathbf{N}=\mathbf{s} /\|\mathbf{S}\|$ is the normalized deviatoric stress. In Equations (8) and (9), $\bar{\eta}=\eta \sigma_{e q} / 3 G \dot{p}$ is the normalized growth rate, where $\sigma_{e q}=\sqrt{\frac{3}{2}}\|\mathbf{s}\|$ and $\tau(\bar{\eta})$ is given by

$$
\tau(\bar{\eta})=h+\frac{3 G \dot{p} \bar{\eta} \Sigma}{\sigma_{e q}}-\frac{3 G \Gamma t_{a} \bar{\eta}}{3 G \Omega \bar{\eta}+\sigma_{e q}}
$$

with $h=\partial \sigma_{e q} / \partial p, \Sigma=\partial \sigma_{e q} / \partial \dot{p}$ and $\Gamma=\partial \sigma_{e q} / \partial t_{a}$ representing respectively the rate of hardening (plastic modulus), the strain rate sensitivity and the dynamic strain ageing capacity. The solution of Equation (8) consists in searching for the first time in a loading process when a real direction $\mathbf{n}$ associated to a rate of growth $\eta$ with positive real part exists. The optimization with respect to $\mathbf{n}$ leads to

$$
a \bar{\eta}^{3}+b \bar{\eta}^{2}+c \bar{\eta}+d=0
$$

where the coefficients are obtained by 


$$
\begin{aligned}
a & =9 G \Sigma \Omega \dot{p}>0 \\
b= & 3\left[3 G \Omega \sigma_{e q}\left(\frac{h}{3 G}+(1+v) N_{2}^{2}\right)+\Sigma \dot{p}\left(\sigma_{e q}+(1+v) G \Omega\left(2-3 N_{2}^{2}\right)\right)-\Gamma t_{a} \sigma_{e q}\right] \\
c & =\sigma_{e q}\left[(1+v)\left\{\Sigma \dot{p}\left(2-3 N_{2}^{2}\right)+3 \sigma_{e q} N_{2}^{2}\right\}+3 h\left\{\sigma_{e q}+(1+v) G \Omega\left(2-3 N_{2}^{2}\right)\right\}\right. \\
& \left.-\Gamma t_{a}(1+v)\left(2-3 N_{2}^{2}\right)\right] \\
d= & (1+v) \sigma_{e q}^{2}\left(2-3 N^{2}\right) \frac{h}{3 G}>0
\end{aligned}
$$

and $N_{2}$ is the intermediate principal value of $\mathbf{N}$. The critical $\mathbf{n}$ is located in the plane $\left(\mathbf{e}_{1}, \mathbf{e}_{3}\right)$, where $\mathbf{e}_{1}$ and $\mathbf{e}_{3}$ are the directions of the major and minor principal stresses. The angle $\theta$ that $\mathbf{n}$ makes with $\mathbf{e}_{1}$ in the plane $\left(\mathbf{e}_{1}, \mathbf{e}_{3}\right)$ is given by

$$
(\operatorname{tg}(\theta))^{2}=\frac{3 \bar{\eta}\left[\sqrt{2-3 N_{2}^{2}}-(1-2 v) N_{2}\right]+2(1+v) \sqrt{2-3 N_{2}^{2}}}{3 \bar{\eta}\left[\sqrt{2-3 N_{2}^{2}}+(1-2 v) N_{2}\right]+2(1+v) \sqrt{2-3 N_{2}^{2}}}
$$

We first note that as $h>0$, the transition from stability to instability cannot occur for $\bar{\eta}=0$ because $d>0$ in Equation (11). To check instability, it is convenient here to use the Routh-Hurwitz criterion. The RouthHurwitz matrix coefficients are in this case $a, b,(b c-a d) / b$ and $(b c-a d) d / b$. As $a$ and $d$ are positive, the boundary of the stability domain is therefore obtained by the signs of the coefficients $b$ and $b c-a d$.

\subsection{Application to the tension test and prediction of the PLC characteristics}

We apply the results to the tension tests considered in the paper. We assume that the tests are homogeneous, at least until the appearance of PLC bands or any instability and consider that the total strain rate $\dot{\varepsilon}$ is constant throughout the test. The constitutive equations reduced for a uniaxial test are solved numerically to obtain all the state variables during the loading process, from which the coefficients $a, b, c$ and $d$ in Equation (12) are determined as functions of strain. We remark here that in the elastic regime the waiting time equals the physical time so that its value at the beginning of the plastic regime is given by

$$
t_{a}\left(t_{0}\right)=t_{0}=\frac{\sigma_{0}}{E \dot{\varepsilon}}
$$


where $t_{0}$ is the time used to reach the yield stress.

Fig 16 shows the evolution of the coefficients $b$ and $b c-a d$ during the tests, and one can observe that these coefficients are always negative in the beginning of the tests, implying that the behaviour is unstable right from the beginning of the plastic regime. This does not comply with the experimental results as shown in Fig 5. We note however that for the two highest strain rates, these coefficients may become positive, while for the other they remain negative throughout the test.

For the tension test, the critical normal directions belong to the cone with axis in the tension loading direction and angle given by Equation (13); the critical orientation $\theta_{c}$ is determined as a function of the critical growth rate $\bar{\eta}_{c}$ and the result is shown in Fig 17 . One can see there that there is only a small influence of this parameter on the orientations and therefore the effects of rate dependency and dynamic strain ageing are very limited on these orientations. We note that the trace of the band on the surface of the specimen makes an angle $\psi$ with the tension axis that varies from $42.5^{\circ}$ and $90^{\circ}$ for all normals $\mathbf{n}$ in the cone.

The critical orientation $\theta_{c}$ is only slightly different from the critical orientation $\theta^{p}$ corresponding to localization for a rate-independent material with the same yield surface as used in the elasto-viscoplastic material model. For the model considered herein, we have

$$
\left(\operatorname{tg}\left(\theta^{p}\right)\right)^{2}=\frac{\sqrt{2-3 N_{2}^{2}}-(1-2 v) N_{2}}{\sqrt{2-3 N_{2}^{2}}+(1-2 v) N_{2}}
$$

and for tension $\left(N_{2}=-1 / \sqrt{6}\right)$ we get

$$
\theta^{p} \approx 47.5^{\circ}
$$

\section{Numerical simulations}

There are several other studies in the literature in which the finite element method has been used to investigate the PLC effect and related phenomena. The morphology of PLC bands in Al-Mg-Si alloys was studied by Zhang et al. [24] using finite element analysis (FEA) and an elasto-viscoplastic constitutive model accounting for DSA. Kok et al. [27]0 used a polycrystal plasticity model embedded in a finite element framework to study the PLC effect in velocity-controlled tension tests, while Graff et 
al. [29][30] compared results from FEA with experiments on U-notched and V-notched specimens for an Al-Li alloy exhibiting DSA. In addition, PLC effects at the crack tip in pre-cracked CT specimens were investigated. They used the same constitutive model as Zhang et al. [24], which is based on McCormick [6][31]. Lasko et al. [32] used a constitutive relation similar to the McCormick model in 3D numerical simulations of flat $\mathrm{Al}-\mathrm{Cu}$ alloy specimens pulled in tension at different strain rates. The numerical results were in agreement with available experimental results. Benallal et al. [33] used a phenomenological elasto-viscoplastic model based on Penning [34] and FEA to study the PLC effect in tension tests with smooth axisymmetric specimens at different strain rates and with U-notched axisymmetric specimens at quasi-static strain rates. The numerical results were in good overall agreement with experimental data from Clausen et al. [1]. Hopperstad et al. [11] used an anisotropic elasto-viscoplastic model including dynamic strain ageing. Lower formability was predicted in the strain rate region in which DSA occurred, and it was concluded that a major reason for this was the increased thickness inhomogeneity that developed during discontinuous plastic flow. Recently, an experimental and numerical investigation of the PLC effect in the aluminium alloy AA5083-H116 was carried out by Benallal et al. [2]. Five different tests with round, prismatic and flat notched specimen geometries were performed. The elastic-viscoplastic constitutive model with dynamic strain ageing presented in section 4.1 was used in full-scale 3D numerical simulations of the physical tests using the explicit finite element analysis. It was shown that the numerical simulations were able to reproduce most of the experimentally observed phenomena with reasonable accuracy.

\subsection{Numerical models}

The numerical study was performed using the explicit solver of LS-DYNA [35]. The model was made using 8-node constant-stress solid elements with one-point integration, and viscous-based hourglass control was applied to avoid zero energy modes. The loading was always applied smoothly to avoid introducing spurious high frequency noise in the simulations (with a rise time of $5 \%$ of the computational time). If a smooth loading was not applied, it was found difficult to separate the PLC serrations from the introduced noise. In all simulations, the left edge of the specimen was fixed, while the right edge was given a prescribed velocity as a function of time similar to the one used in the corresponding experimental test (see Table 1). All specimens were pulled $30 \mathrm{~mm}$, i.e. well beyond necking, before the simulation was terminated. Since the simulations involved low strain rates, mass scaling was adopted to increase the stable time step and thus reduce the computational time. Earlier simulations by the authors have indicated that the effect of mass 
scaling on the PLC behaviour is in general small [11][33]. It was also controlled in all simulations that the kinetic energy was only a small fraction of the internal energy of the analyzed system. The mass was scaled to keep about the same computational time independent of strain rate. Note that these simulations are demanding both with respect to computation time and data storage. To be able to describe the morphology of single PLC bands in any detail, 10000 data dumps were saved from each simulation. It should finally be mentioned that the stiffness of the testing machine has not been included in these simulations (i.e. the stiffness of the test machine is assumed infinite). Ideally, springs with the correct test machine stiffness should have been introduced between the specimen and the boundary, but this is outside the scope of the present study.

The finite element model used for all the simulations is given in Fig 18. The geometry of the model was identical to the geometry used in the corresponding experimental tests (see Fig 1). The whole gage length of the specimen was modelled, using an element size of $0.5 \times 0.5 \times 0.5 \mathrm{~mm}^{3}$. This gave 4 elements over the thickness, 30 elements over the width and a total of 24000 elements for the whole specimen.

\subsection{Numerical results}

Fig 19 (top) displays force versus displacements curves for the five tests T1, T2, T3, T4 and T5 as obtained from the simulations. If compared with the experimental results shown in Fig 2, the overall agreement is found to be reasonable. However, a closer look reveals some disagreements. In particular, the simulations are not able to reproduce the critical strain for initiation of the stress serrations, which is a result of the simplicity of the adopted constitutive model. Further, in the simulation of the test at an overall strain rate of about $5 \cdot 10^{-5} \mathrm{~s}^{-1}$, i.e. test $\mathrm{T} 1$, no serrations are seen and the force-displacement curve is smooth. The reason for this is that at this low strain rate, we are actually outside the region of negative strain-rate sensitivity as predicted by the calibrated constitutive relation. Thus, no PLC bands or jerky flow appears in the simulations, and the strain-rate sensitivity is indeed positive.

From the numerical strain gages, having the same location as the optical strain gages, the local nominal strain versus time during straining is registered. Results for location X are given in Fig 19 (bottom). If compared to the experimental results in Fig 6 more bands are found in the simulations, and less variation between tests at different strain rates is seen. The increased number of bands until necking indicates a higher band velocity in the simulations than in the tests, as will be discussed further below. Based on these curves, an estimate of the band velocity, band width and strain rate inside the PLC band can be obtained. The band velocity $v_{b}$ is found by dividing the length travelled by the band $L_{b}$ by the time interval $\Delta t$ between two 
successive strain increments, i.e. the band velocity is estimated as $v_{b}=L_{b} / \Delta t$. In these estimations, $L_{b}$ was taken as the parallel length of the gage section which was $80 \mathrm{~mm}$. The average strain rate $\dot{\varepsilon}_{b}$ inside the PLC band is given by the slope of the strain increments. By assuming that all plastic deformation takes place inside the propagating band and that the strain is approximately uniform within the band, the band width $w_{b}$ is connected to the strain rate inside the band $\dot{\varepsilon}_{b}$, the imposed strain rate $\dot{\varepsilon}$ and the length travelled by the band $L_{b}$ as $w_{b} \approx\left(\dot{\varepsilon} / \dot{\varepsilon}_{b}\right) L_{b}$. Using this relation, rough estimates of the band width has been obtained.

Fig 11 compares the experimental and predicted band velocities for the four simulations exhibiting the PLC effect. In general, the agreement is satisfactory, but the simulations predict somewhat higher band velocities than seen in the experiments. However, the decreasing band velocity with increasing strain is captured correctly. The experimentally obtained and predicted strain rates inside the bands are compared in Fig 13. Again, the simulations give higher values than the experiments, but owing to the scatter of the data clear conclusions can not be drawn. However, the strain rate inside the band is much higher than the applied overall strain rate also in the simulations. Fig 15 shows the band width from experiments and simulations. In the simulations the band width is generally between 2 and $6 \mathrm{~mm}$, while it is generally somewhat larger in the experiments. The scatter in the data prohibits more detailed comparisons.

Examples of PLC bands in the simulation of test T4 are provided in Fig 20. It is seen that there may be one or several bands occurring simultaneously along the specimen gage length, while the band width is around $4 \mathrm{~mm}$. The band inclination was measured on such fringe plots for all simulations exhibiting PLC bands, and the results are plotted together with the tests in Fig 12. In the simulations, the band angle is between $54^{\circ}$ and $57^{\circ}$, while it is somewhat larger in the tests. This discrepancy is believed to be partly caused by the anisotropy of the material which is not accounted for in the simulations (see Hopperstad et al. [11]).

The energy equation for the elastic-viscoplastic constitutive model reads

$$
\rho C_{p} \dot{T}=T \frac{\partial \boldsymbol{\sigma}}{\partial T}: \dot{\boldsymbol{\varepsilon}}^{e}+T \frac{\partial R}{\partial T} \dot{p}+\boldsymbol{\sigma}: \dot{\boldsymbol{\varepsilon}}^{p}+R \dot{p} \approx \chi \boldsymbol{\sigma}: \dot{\boldsymbol{\varepsilon}}^{p}
$$

where $\rho$ is the density, $C_{p}$ is the specific heat, $T$ is the temperature, $\chi$ is the Taylor-Quinney coefficient, while $\dot{\boldsymbol{\varepsilon}}^{e}$ and $\dot{\boldsymbol{\varepsilon}}^{p}$ are respectively the elastic and plastic strain rate tensors. To obtain the latter equality in Equation (17), some simplifying assumptions were made. As the temperature variation is rather small, the variation of stress and hardening with temperature were neglected and the dissipation is written as a fraction 
of the plastic work through the Taylor-Quinney coefficient. Further, thermal expansion and heat conduction were also neglected.

In this framework, and assuming uniaxial tension, the temperature increment $\Delta T$ within a time increment in the simulations is estimated as

$$
\Delta T=\chi \frac{\left(\sigma_{n+1}+\sigma_{n}\right)\left(\varepsilon_{n+1}^{p}-\varepsilon_{n}^{p}\right)}{2 \rho C_{p}}
$$

where the coefficients $\chi, \rho$ and $C_{p}$ are given in Table 5. The total strains in the beginning and at the end of the time increment are

$$
\varepsilon_{n}=\varepsilon_{n}^{p}+\frac{\sigma_{n}}{E}, \quad \varepsilon_{n+1}=\varepsilon_{n+1}^{p}+\frac{\sigma_{n+1}}{E}
$$

and thus the plastic strain increment reads

$$
\Delta \varepsilon^{p}=\varepsilon_{n+1}^{p}-\varepsilon_{n}^{p}=\left(\varepsilon_{n+1}-\varepsilon_{n}\right)-\frac{1}{E}\left(\sigma_{n+1}-\sigma_{n}\right)
$$

The temperature increment $\Delta T$ may now be calculated as

$$
\Delta T=\chi \frac{\left(\sigma_{n+1}+\sigma_{n}\right)\left(\left(\varepsilon_{n+1}-\varepsilon_{n}\right)-\frac{1}{E}\left(\sigma_{n+1}-\sigma_{n}\right)\right)}{2 \rho C_{p}}
$$

Using this approach, the temperature increase inside the band for all tests has been calculated, and the results are presented in Fig 14 where they are compared to the experimental measurements. It is seen that the agreement is good, and the temperature increase inside the band is typically $0.5-2^{\circ} \mathrm{C}$. 


\section{A. Benallal, T. Berstad, T. Børvik, O.S. Hopperstad \& R. Nogueira de Codes}

\section{Discussion}

In the finite element analysis, serrations and PLC bands are not predicted for test T1 with strain rate about $5 \times 10^{-5} \mathrm{~s}^{-1}$ (Fig 19). The reason for this is the calibration of the constitutive relation which was based on tensile tests with strain rates from $10^{-5}$ to $1000 \mathrm{~s}^{-1}$, using a simple analytical approach presented in [2][11]. With this approach, the steady-state strain-rate sensitivity is found to be positive for this low strain rate, and thus serrations and propagating bands are not predicted. It is believed that a more refined calibration of the model based on inverse modelling with finite element analysis would lead to improved results in the lower range of strain rates. It should also be mentioned that simulations have shown that if the overall strain rate is slightly increased (to about $7 \times 10^{-5} \mathrm{~s}^{-1}$ ), serrations also appear at these low strain rates. Furthermore, the constitutive model is not able to account for the critical strain observed in the experimental tests, and serrations and PLC bands are predicted right from the beginning of the plastic range (Fig 19). This is also found in the linear stability analysis in section 4.3. The reason is that the material parameters governing dynamic strain ageing were all taken to be constant in order to simplify the parameter identification. By letting these parameters evolve with plastic straining, see e.g. Zhang et al. [24], it is possible to account for the critical strain and thus getting better agreement with the experiments in the linear stability analysis and the finite element simulations. Based on these considerations, it seems that the adopted model is somewhat rudimentary if the aim is to perform detailed studies of the PLC effect using finite element analysis. However, it may be sufficient in large-scale simulations of plastic forming for industrial applications [11].

The band velocity is consistently over-estimated in the numerical simulations, but the scaling of the band velocity with the overall strain rate was correctly captured (Fig 11). Furthermore, the band velocity is seen to decrease with increasing strain and thus with decreasing hardening rate in both tests and simulations. The over-estimation of the band velocity may have several sources. In the simulation, the band velocity was based on the strain-time curve in one numerical gage located at the centre of the specimen, assuming that the band travels a distance equal to the parallel length of the gage section. Fig 6 shows that there are variations between the strain-time curves at different locations in the experiments. Further, the distance travelled by the band will probably vary, and the adopted value is nothing but a rough estimate. Hence, it should not be expected that the estimated band velocity at each strain rate is very accurate, but the adopted procedure should be able to describe the trends with varying strain and strain rate, which is indeed the case.

The orientation of the band is between $54^{\circ}$ and $57^{\circ}$ in the simulations, while somewhat higher values are found experimentally (Fig 12). It should be noted that AA5083-H116 exhibits some anisotropy [1]; in 
particular in terms of the strain ratios (or Lankford coefficients). In the rolling direction, the strain ratio is about 0.43 , which is a significant deviation from unity, the value expected for an isotropic material. If it is assumed that the band is directed along the line of zero extension, which is reasonable for the given specimen geometry, the band orientations should be $54.7^{\circ}$ for an isotropic material and $61.3^{\circ}$ for AA5083-H116 [11]. Hence, it is reasonable to conclude that the under-estimation of the band angle is caused by neglecting the plastic anisotropy in the numerical simulations. The linear stability analysis is only able to give a range of orientations to which possible band orientations are limited. The observed band orientations are within the predicted range. It is believed that by accounting for the plastic anisotropy, the predicted range could be reduced.

The scaling of the strain rate inside the band with the overall strain rate is accurately predicted in the numerical simulations (Fig 13). It is found that the strain rate inside the band is about two orders of magnitude higher than the overall strain rate. Compared with the experiments, this is a rather high ratio. However, it should be noted that since the strain rate inside the band is estimated from the slope of the straintime curve at a given location as the band passes by, see Fig 6, there are significant uncertainty linked to these estimates both from experiments and simulations. Compared with the duration of the test, the time elapsed while the band passes by is small, and relatively few data points are logged during this time interval. As already mentioned, it is seen from Fig 6 that there are spatial variations in the strain-time curves, which also adds to the uncertainty. Accordingly, the main aim with this assessment was to compare the experimentally and numerically obtained scaling of the strain rate within the band with increasing overall strain rate.

The temperature increase inside the band seems to be in the order of $1^{\circ} \mathrm{C}$ both in tests and simulations, but the scatter is too large to conclude with respect to the accuracy of the predicted results (Fig 14). However, the simulations show that the temperature increment within the band increases with straining, which means that the strain carried by the band increases with increasing strain and decreasing hardening rate. This is consistent with most experimental findings and is also seen in Fig 6. From the simulations, it seems that the temperature increase within the band is about the same for all overall strain rates, which is reasonable since adiabatic conditions were assumed and the viscous stress contribution to plastic dissipation is relatively small.

The final band characteristic measured was the band width. Both the experimentally and numerically based measurements exhibit significant scatter, and band widths between 1 and $20 \mathrm{~mm}$ are seen in Fig 15 . This hampers the assessment of the simulations. While the band width was measured on plots like Fig 9 for the experiments, it was estimated from the relation $w_{b} \approx\left(\dot{\varepsilon} / \dot{\varepsilon}_{b}\right) L_{b}$ for the simulations. Since there are considerable uncertainty linked to both the distance travelled by the band $L_{b}$ and the strain rate inside the 
band $\dot{\varepsilon}_{b}$, we should only expect rough estimates on the band width from the simulations. It is further noted in Fig 20 that multiple bands were sometimes observed in the simulations, while experimentally this was not the case. The reason for this discrepancy is not known. In order to substantiate the estimated band widths shown in Fig 15, direct measurement of the band width on plots like those shown in Fig 20 was carried out. It was found that the band width generally was between 2 and $6 \mathrm{~mm}$ and seemed to increase somewhat with increased strain. The band width was found to be in the same range also when two bands were present along the gage length.

A study of the mesh sensitivity was out of scope of the current paper. However, it was concluded by Zhang et al. [24] that predicted band characteristics were not particularly mesh sensitive. Benallal et al. [33] conducted a study of mesh size dependence in simulations of tension tests with smooth axisymmetric specimens using a phenomenological elasto-viscoplastic model accounting for the PLC effect based on Penning [34]. Significant mesh size effects were seen if the mesh was too coarse. In the current study, a relatively fine mesh is used in all simulations with a characteristic element size of $0.5 \mathrm{~mm}$. The number of eight-node solid elements with one-point integration in the parallel part of the gage area is 19200. In comparison, Zhang et al. [24] used 2100 eight-node, incompatible-mode solid elements in the finest mesh included in their study on mesh sensitivity. It is therefore believed that the influence of the mesh is not particularly significant with respect to the predicted band characteristics.

Another issue with explicit finite element simulations of quasi-static problems is the use of mass scaling, which is necessary to obtain manageable run times and a reasonable number of cycles. Limited studies on mass scaling performed in [11][33] indicate that the influence on the predicted PLC serrations is limited for reasonable values of the scaling factor. Owing to the unmanageable run times and large number of cycles for low strain rates and low mass scaling factors, it is not an easy task to perform a detailed study on this issue. It should further be noted that it is neither straightforward to use an implicit solver to simulated the PLC effect, because the strain rate inside the band may be several orders of magnitude higher than the overall strain rate (see Fig 13). This calls for small load increments to properly discretize the problem in time. Furthermore, it is difficult to find the equilibrium configurations because of the high-frequency force serrations. Hence, explicit simulations seem to be well suited for the actual problem, but the detailed influence of mass scaling is still an open question. 


\section{Conclusions}

In this paper, we have presented an experimental, theoretical and numerical study of the effects of strain rate on the PLC characteristics of the aluminium-magnesium alloy AA5083-H116. In the experiments, digital image correlation and digital infrared thermography prove to be promising tools for further investigations and, particularly, for problems involving multiaxial states of stress. These recent techniques allow detailed observations of the PLC band behaviour, including their propagation, surface structure and velocity.

The linear perturbation approach is able to detect the onset of instability and the orientation of the bands, but cannot give information on the width of the bands. Consideration of thermo-mechanical couplings and heat conduction furnishes a first step in determining the width of the bands. The onset of instability obtained does not fit with experimental results. The discrepancy is attributed to the constitutive model in which the plastic strain dependence of the parameters governing dynamic strain ageing is neglected. Regarding the orientations of the bands, the approach predicts a wide range of potential normals for the tension test, and the results from experiments and numerical simulations fall within this range. It is believed that the predicted range can be reduced by including plastic anisotropy in the constitutive model.

Regarding the three-dimensional numerical simulations of the physical tests using explicit finite element analysis, it has been shown that the simulations are able to reproduce many of the experimentally observed phenomena with good accuracy (at least from an engineering point of view). In particular, the scaling of band velocity and the strain rate within the band with the overall strain is captured, and also the evolution of the band velocity and temperature within the band with increasing strain is realistically described. The main discrepancies are failure to predict the critical strain for onset of serrated yielding and serrated yielding for the lowest overall strain rate, which are in turn attributed to the lack of strain dependence of the parameters governing dynamic strain aging and the simple, analytical approach used to calibrate the model.

\section{Acknowledgement}

The authors would like to thank Francois Hild and Stephane Roux for discussions concerning digital image correlation and thermography. This work was supported by Ecole Normale Supérieure de Cachan, the Structural Impact Laboratory (SIMLab), Centre for Research-based Innovation (CRI) at the Norwegian University of Science and Technology (NTNU), CNRS through PICS-3052, the French-Norwegian Foundation and the Brazilian Ministry of Education through CAPES. 
A. Benallal, T. Berstad, T. Børvik, O.S. Hopperstad \& R. Nogueira de Codes

\section{References}

[1] A.H. Clausen, T. Børvik, O.S. Hopperstad and A. Benallal. Flow and fracture characteristics of aluminium alloy AA5083-H116 as function of strain rate, temperature and triaxiality. Mater. Sci. Eng. A364 260-272 (2004).

[2] A. Benallal, T. Berstad, T. Børvik, O.S. Hopperstad, I. Koutiri and R. Nogueira de Codes. An experimental and numerical investigation of the behaviour of AA5083 aluminium alloy in presence of the Portevin-Le Chatelier effect. Int. J. Plasticity, doi:10.1016/j.ijplas.2008.03.008 (2008).

[3] A.H. Cottrell. A note on the Portevin-Le Chatelier effect. Philosophical Magazine (seventh series) 44 (335), 829-832 (1953).

[4] A.H. Cottrell. Dislocations and Plastic Flow in Crystals. University Press, Oxford (1953).

[5] L.P. Kubin, Y. Estrin. Portevin-Le Chatelier effect in deformation with constant stress rate. Acta Metallurgica 33 (3), 397-407 (1985).

[6] P.G. McCormick. Theory of flow localisation due to dynamic strain ageing. Acta Metallurgica 36 (12), 3061-3067 (1988).

[7] M. Wagenhofer, M.A. Erickson-Natishan, W.R. Armstrong and F.J. Zerilli. Influences of strain rate and grain size on yield and serrated flow in commercial AlMg-alloy 5086. Scripta Materialia 41, 1177-1184 (1999).

[8] E. Rizzi and P. Hähner. On the Portevin-Le Chatelier effect: theoretical modeling and numerical results. International Journal of Plasticity 20 121-165 (2004).

[9] J. Kang, D.S. Wilkinson, J.D. Embury, M. Jain and A.J. Beaudoin. Effect of type-B Portevin-Le Chatelier bands on the onset of necking in uniaxial tension of strip cast AA5754 sheets. Scripta Materialia 53 499-503 (2005). 
[10] J. Kang, D.S. Wilkinson, M. Jain, J.D. Embury, A.J. Beaudoin, S. Kim, R. Mishira and A.K. Sachdev. On the sequence of inhomogeneous deformation processes occurring during tensile deformation of strio cast AA5754. Acta Materialia 54 209-218 (2006).

[11] O.S. Hopperstad, T. Børvik, T. Berstad, O.G. Lademo, A. Benallal. A numerical study on the influence of the Portevin-Le Chatelier effect on necking in an aluminium alloy. Modelling and Simulation in Materials Science and Engineering 15, 747-772 (2007).

[12] K. Chihab, Y. Estrin, L.P. Kubin, J. Vergnol. The kinetics of the Portevin-Le Chatelier bands in an Al5at\%Mg alloy. Scripta Metallurgica 21, 203-208 (1987).

[13] Q. Zhang, S. Toyooka, Z. Meng, Safrapedi. Study of propagation and pulsation of clip band using dynamic digital speckle Interferometry. SPIE 3385 389-398 (1999).

[14] Q. Zhang, Z. Jiang, H. Jiang, Z. Chen, X. Wu. On the propagation and pulsation of Portevin-Le Chatelier deformation bands: An experimental study with digital speckle pattern metrology. Int. J. Plasticity 21 2150-2173 (2005).

[15] M.A. Sutton, W.J. Wolters, WH. Peters, W.F. Ranson, S.R. McNeill. Determination of displacements using an improved digital correlation method. Image Vis Comput 1(3):133-139 (1983).

[16] W. Tong, H. Tao, N. Zhang and G. Louis. Hector Jr. Time-resolved strain mapping measurements of individual Portevin-Le Chatelier deformation bands. Scripta Materialia 53, 97-92 (2005).

[17] F. Hild, S. Roux. Digital image correlation: from measurement to identification of elastic properties - A review. Strain 42, 69-80 (2006).

[18] G. Besnard, F. Hild, S. Roux. "Finite-Element" Displacement Fields Analysis from Digital Images: Application to Portevin-Le Châtelier Bands. Experimental Mechanics 46, 789-803 (2006). 
[19] W. Tong and N. Zhang. On serrated plastic flow in an AA5052-H32 sheet. ASME Journal of Engineering Materials and Technology 129, 332-341 (2007).

[20] A. Ziegenbein. Laserextensometrische Untersuchungen des Portevin-Le Châtelier-Effekts an einer CuAl-Legierung. Doctoral Dissertation, Technische Universität Braunschweig, Institut für Metallphysik und Nukleare Festkörperphysik, D-38106 Braunschweig, Deutschland, Cuvillier Verlag, Göttingen (2000).

[21] N. Ranc and D. Wagner. Some aspects of Portevin-Le Chatelier plastic instabilities investigated by infrared pyrometry. Materials Science and Engineering A394 87-95 (2005).

[22] G. Besnard, F. Hild, J.M. Lagrange, S. Roux, C. Voltz. Contact-free characterization of materials used in detonics experiments, Reviews, Review 145, 101-114 (2007).

[23] H. Louche, P. Vacher, R. Arrieux. Thermal observations associated with the Portevin-Le Chatelier effect in an Al-Mg alloy. Materials Science and Engineering A404 188-196 (2005).

[24] S. Zhang, P.G. McCormick and Y. Estrin. The morphology of Portevin-Le Chatelier bands: Finite element simulation for Al-Mg-Si. Acta Materialia 49 1087-1094 (2001).

[25] S.D.J. Mesarovic. Dynamic strain aging and plastic instabilities. Journal of the Mechanics and Physics of Solids 43 671-700 (1995).

[26] A. Benallal. Perturbation and stability of rate dependent solids. Eur. J. Mech. A Solids 19, 45-60 (2000).

[27] S. Kok, A.J. Beaudoin, D.A. Tortorelli and M. Lebyodkin. A finite element model for the Portevin-Le Chatelier effect based on polycrystal plasticity. Modelling Simul. Mater. Sci. Eng. 10 745-763 (2002).

[28] S. Kok, M.S. Bharathi, A.J. Beaudoin, C. Fressengeas, G. Ananthakrishna, L.P. Kubin and M. Lebyodkin. Spatial coupling in jerky flow using polycrystal plasticity. Acta Materialia 51 3651-3662 (2003). 
[29] S. Graff, S. Forest, J.L. Strudel, C. Prioul, P. Pilvin and J.L. Béchade. Strain localization phenomena associated with static and dynamic strain aging in notched specimens: experiments and finite element simulations. Materials Science and Engineering A 387-389 181-185 (2004).

[30] S. Graff, S. Forest, J.L. Strudel, C. Prioul, P. Pilvin and J.L. Béchade. Finite element simulations of dynamic strain ageing effects at V-notches and crack tips. Scripta Materialia 52 1181-1186 (2005).

[31] P.G. McCormick. Numerical simulation of the Portevin-Le Châtelier effect. In: Kettunen, P.O., Lepistö, T.K., Lehtonen, M.E. (Eds.), Proc. of ICSMA 8, Vol. 1. Pergamon Press, pp. 409-414 (1988).

[32] G. Lasko, P. Hähner and S. Schmauder. Finite element simulation of the Portevin-LeChatelier effect. Modelling and Simulation in materials Science and Engineering 13 645-656 (2005).

[33] A. Benallal, T. Berstad, T. Børvik, A.H. Clausen and O.S. Hopperstad. Dynamic strain aging and related instabilities: experimental, theoretical and numerical aspects. European Journal of Mechanics - A/Solids 25 397-424 (2006).

[34] P. Penning. Mathematics of the Portevin-Le Chatelier effect. Acta Metallurgica 29 1169-1175 (1972).

[35] J.O. Hallquist. LS-DYNA keyword user's manual, version 970. Livermore Software Technology Corporation, 2003. 


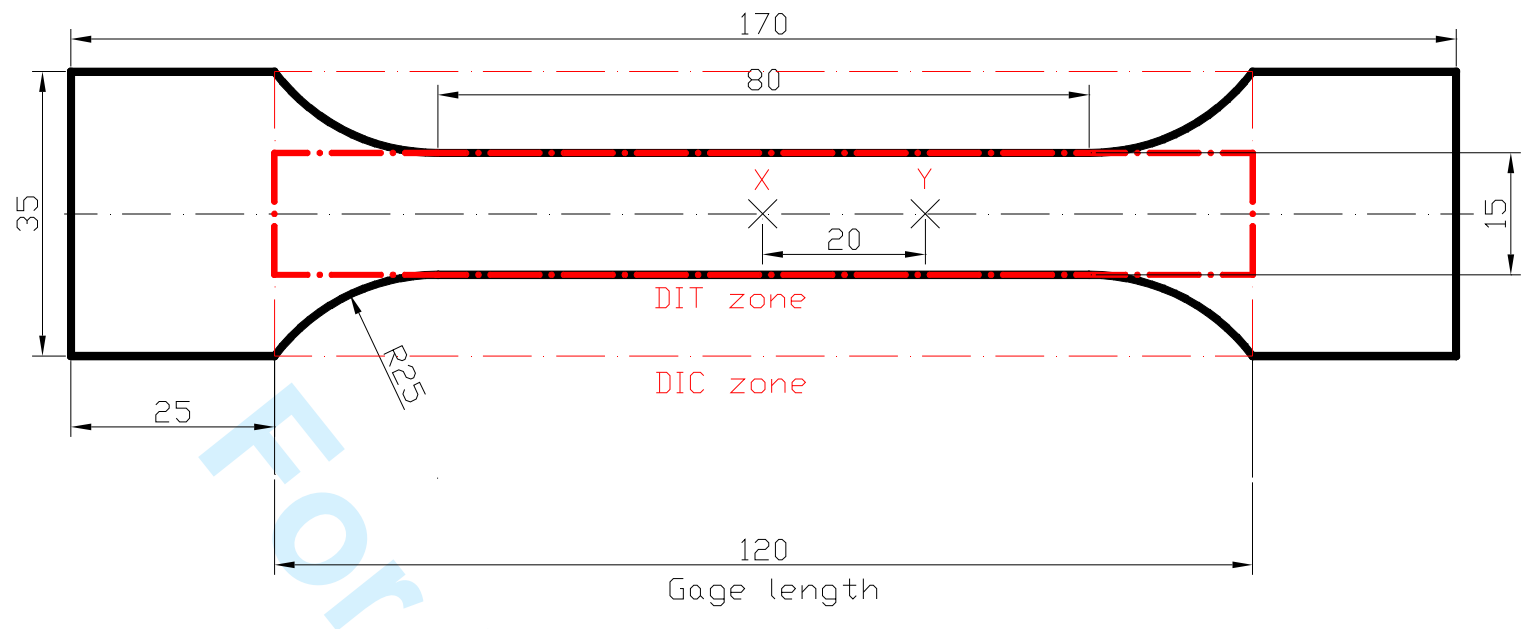

Fig 1: Smooth, flat specimen used in the investigation. For all tests, the specimen was gripped at the same 120 mm gage length. The bold dashed area is the imaged zone in digital infrared thermography, while the thin dashed area is the zone imaged in digital image correlation. $\mathrm{X}$ and $\mathrm{Y}$ are the locations used for presenting some of the experimental results. 


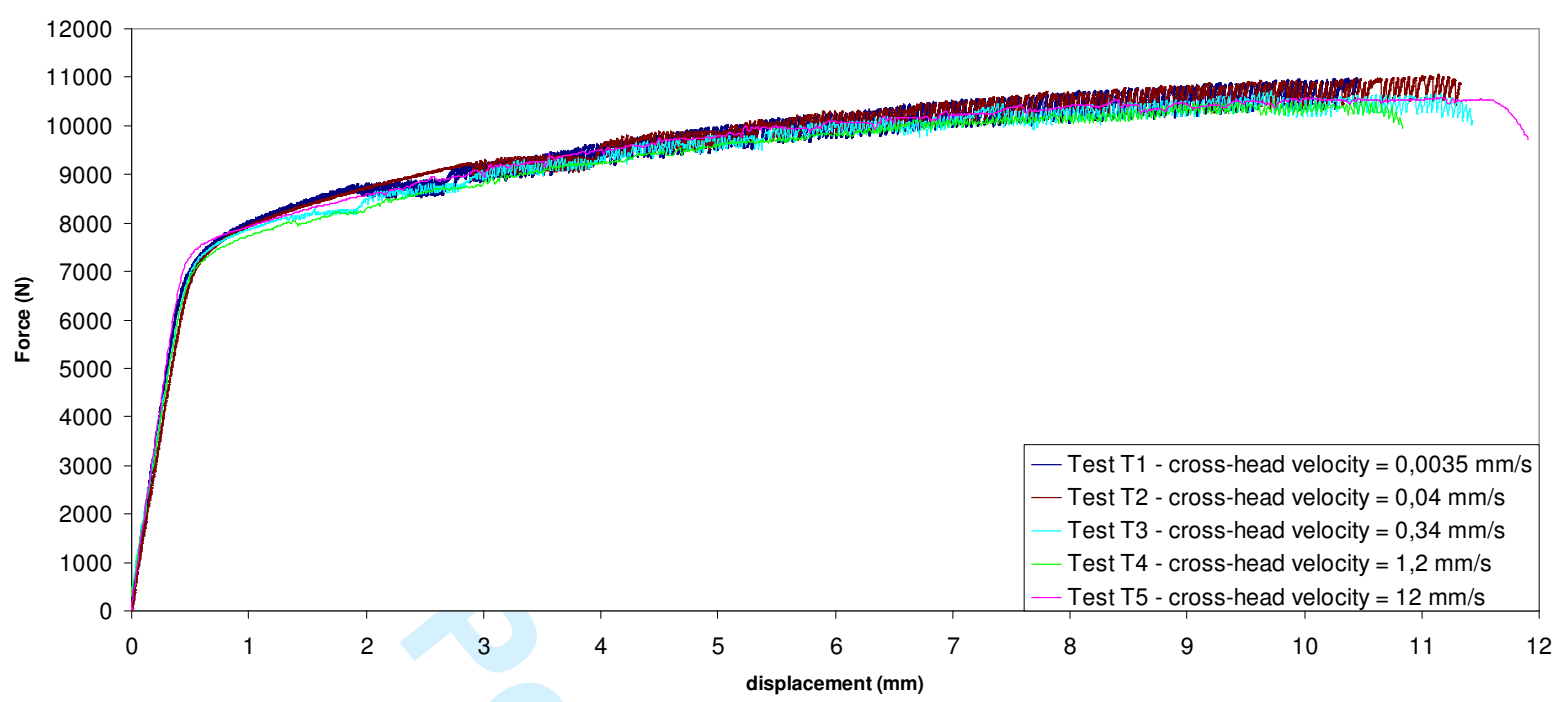

Fig 2: Force versus displacement curves for the five tests (T1, T2, T3, T4 and T5). 
A. Benallal, T. Berstad, T. Børvik, O.S. Hopperstad \& R. Nogueira de Codes

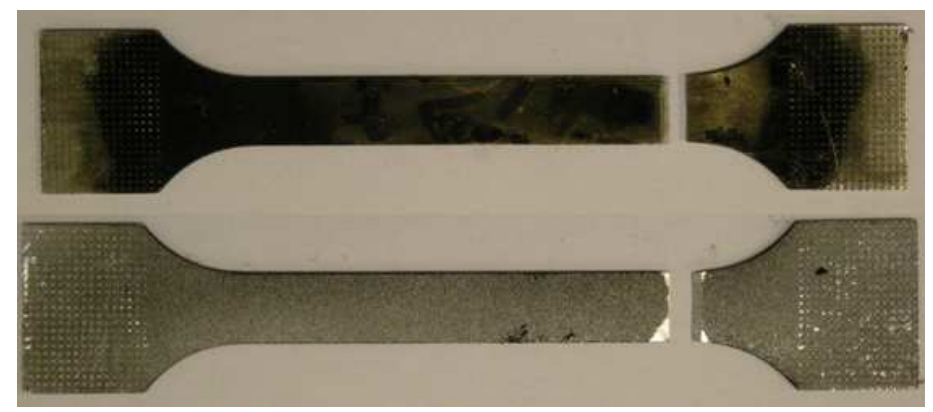

Test T1

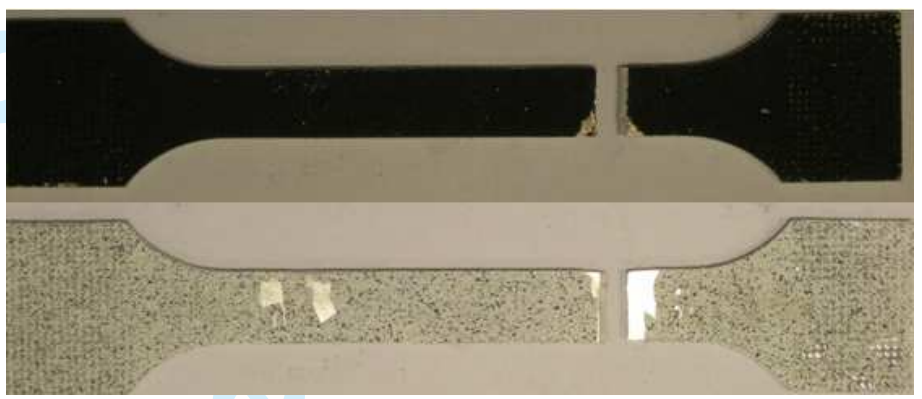

Test T2

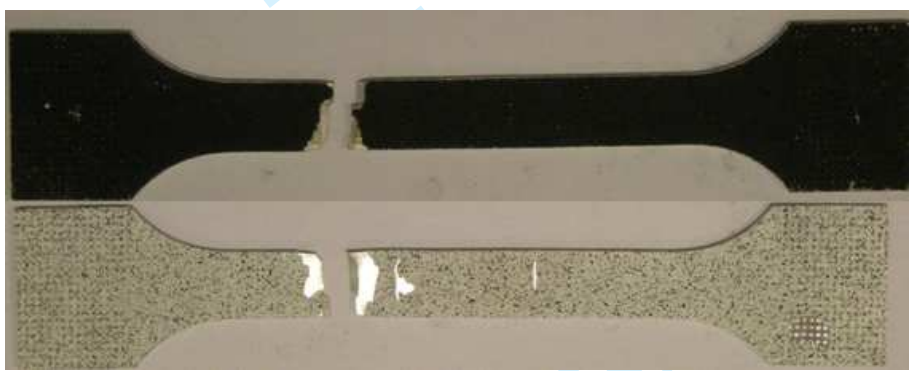

Test T3

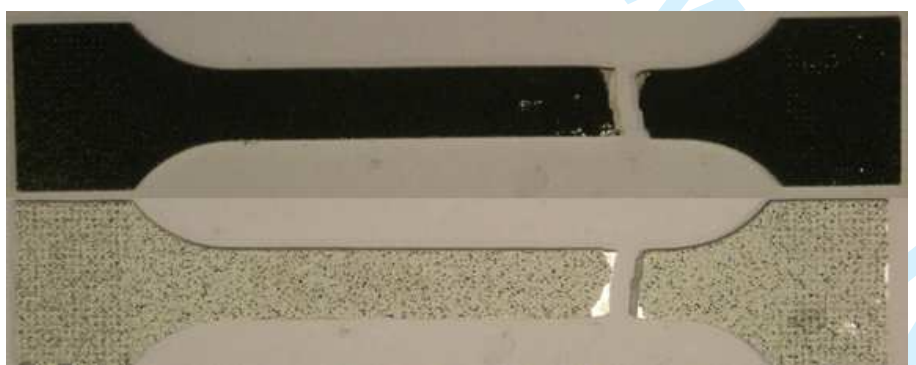

Test T4 
Effects of strain rate in the characteristics of PLC deformation bands for AA5083-H116 aluminium alloy

1

2

3

4

5

6

7

8

9

10

11

12

13

14

15

16

17

18

19

20

21

22

23

24

25

26

27

28

29

30

31

32

33

34

35

36

37

38

39

40

41

42

43

44

45

46

47

48

49

50

51

52

53

54

55

56

57

58

59

60

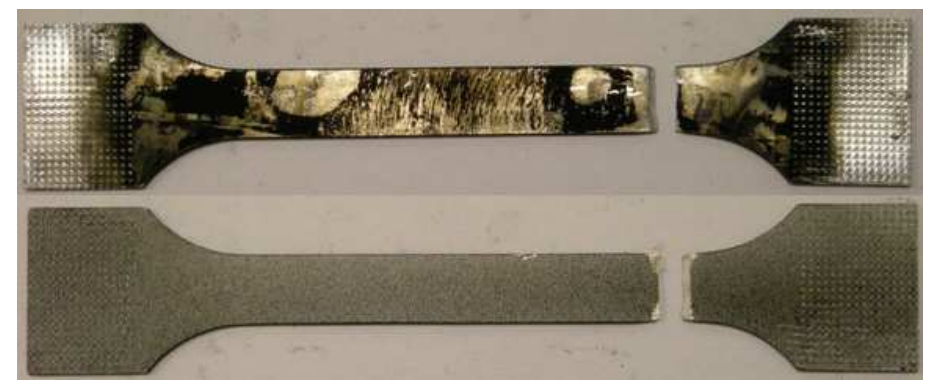

Test T5

Fig 3: Fractured specimens from tests T1, T2, T3, T4 and T5. Some necking is observed in tests T3, T4 and T5. All specimens exhibit shear failure through the thickness. 
A. Benallal, T. Berstad, T. Børvik, O.S. Hopperstad \& R. Nogueira de Codes
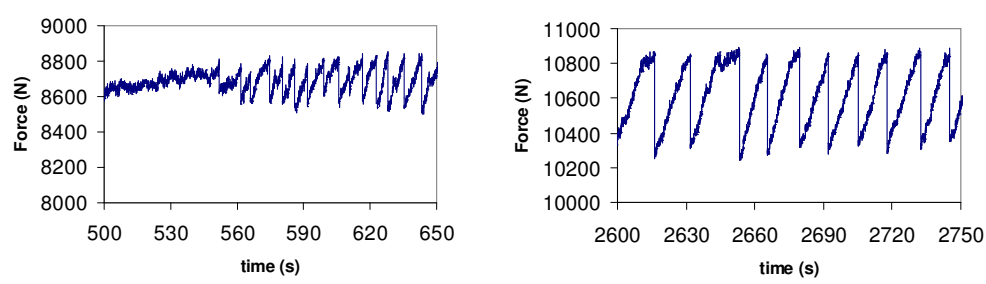

\section{Test T1}
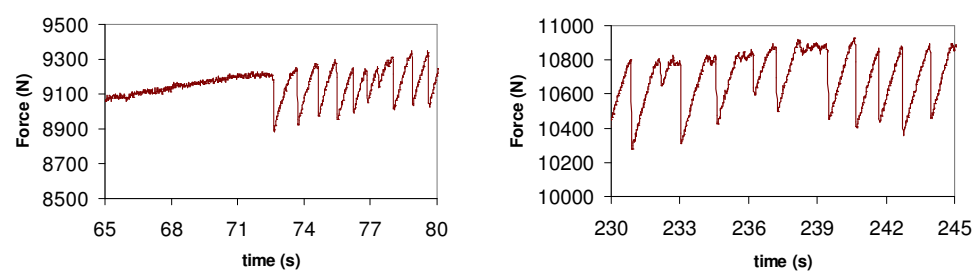

Test T2
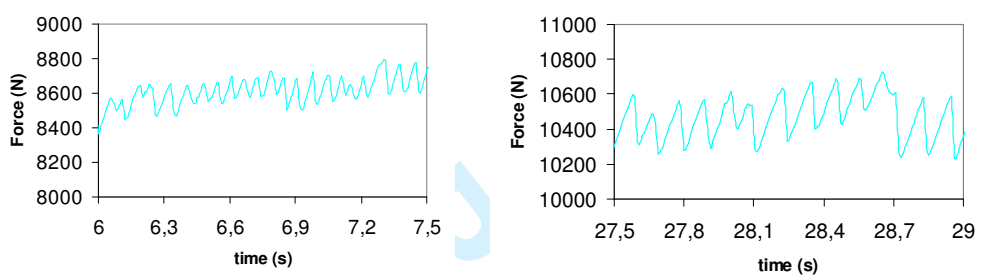

\section{Test T3}
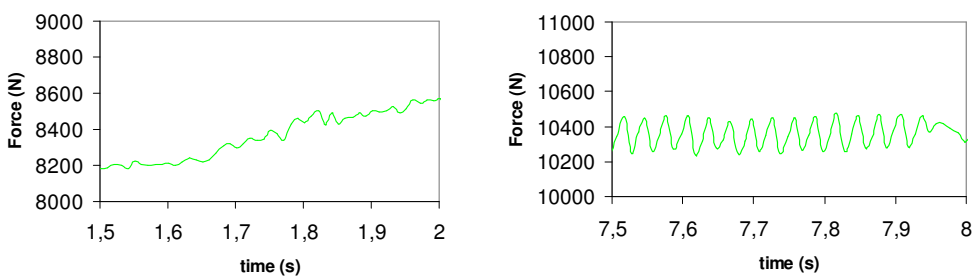

\section{Test T4}
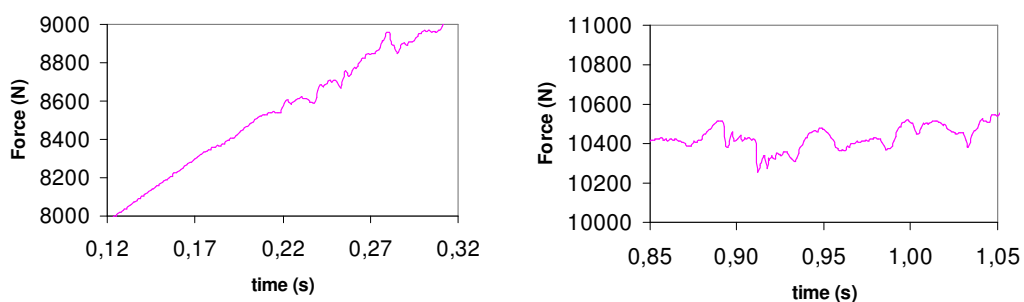

\section{Test T5}

Fig 4: Force versus time curves for tests T1, T2, T3, T4 and T5 showing serrations characteristics. These curves are plotted in the beginning of the test (left) where one can see the critical strain needed for the PLC effect to occur, and close to the end of the test (right). 
Fig 5: Critical strains for the occurrence of the PLC effect versus overall strain rate as obtained from the stress-strain curves, digital image correlation and digital infrared thermography. 
A. Benallal, T. Berstad, T. Børvik, O.S. Hopperstad \& R. Nogueira de Codes

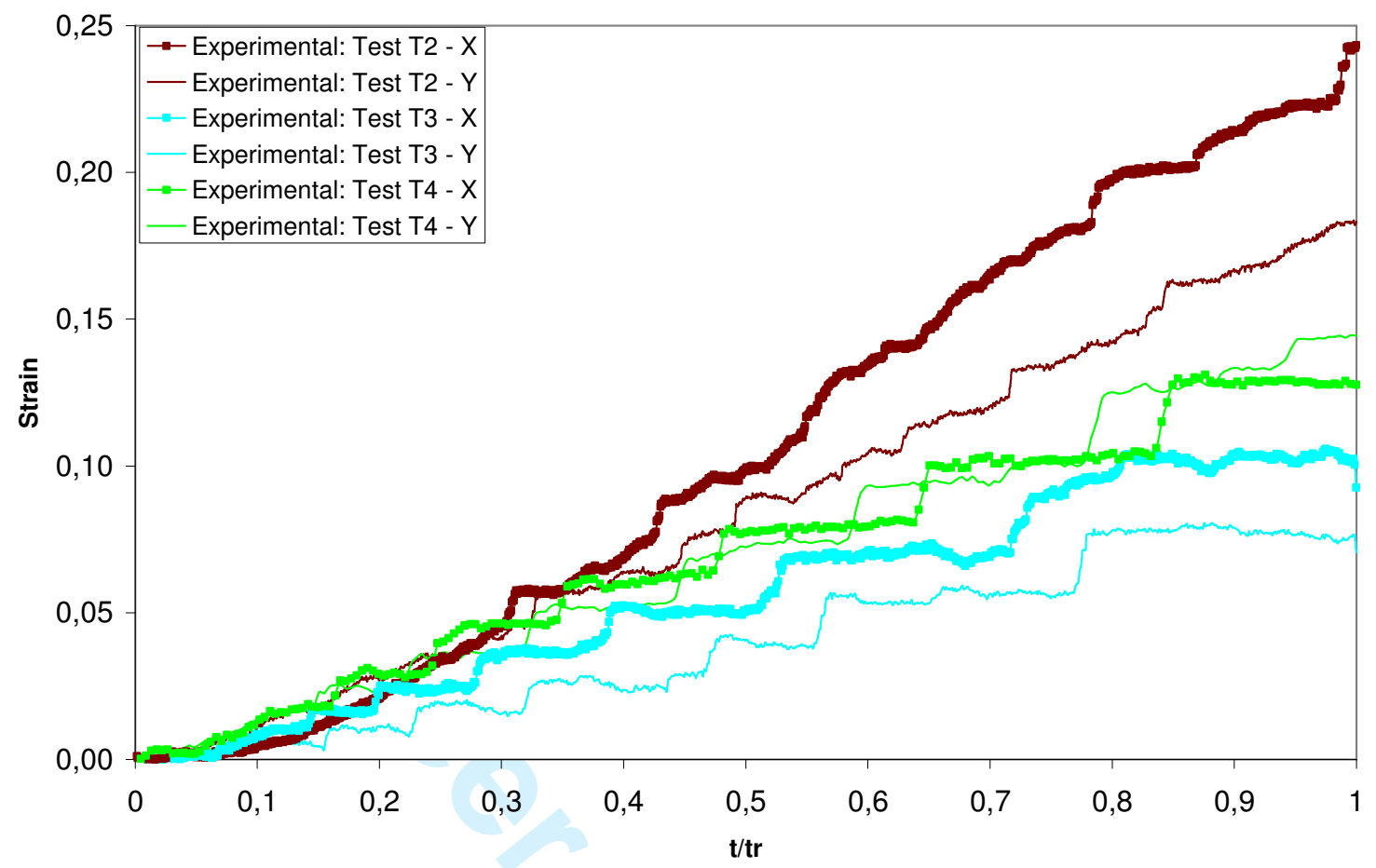

Fig 6: Strain histories at locations $\mathrm{X}$ and $\mathrm{Y}$ shown in Fig. 1 for tests T2, T3 and T4, where the time axis has been normalized with the time to failure $t_{r}$ for each test. 


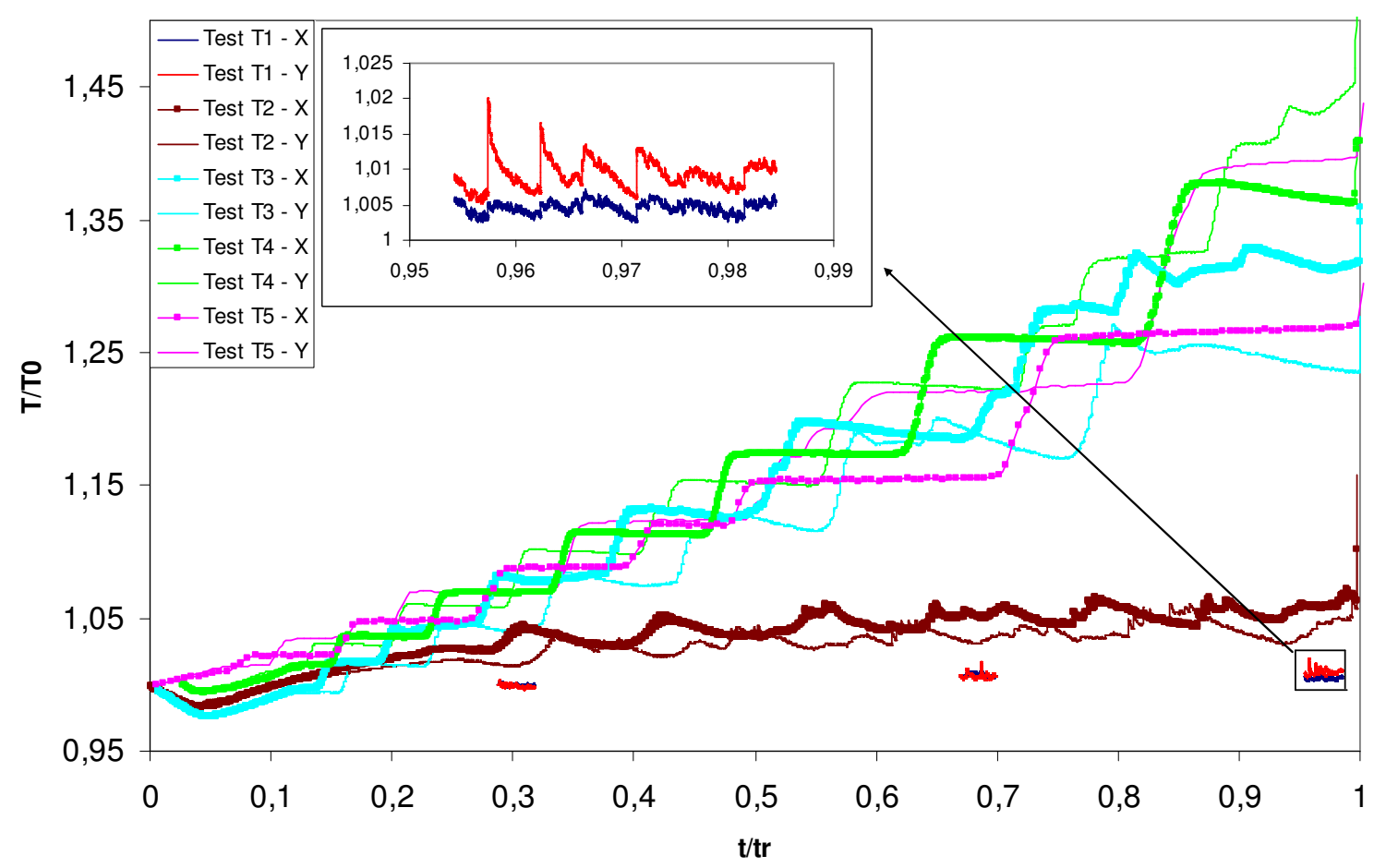

Fig 7: Temperature histories at locations $\mathrm{X}$ and $\mathrm{Y}$ for tests T1, T2, T3, T4 and T5. The temperature axis is normalized with the room temperature, while the time axis is normalized with the time to failure $t_{r}$ for each test. For test T1, only those time intervals where data acquisition was performed are presented. 
A. Benallal, T. Berstad, T. Børvik, O.S. Hopperstad \& R. Nogueira de Codes
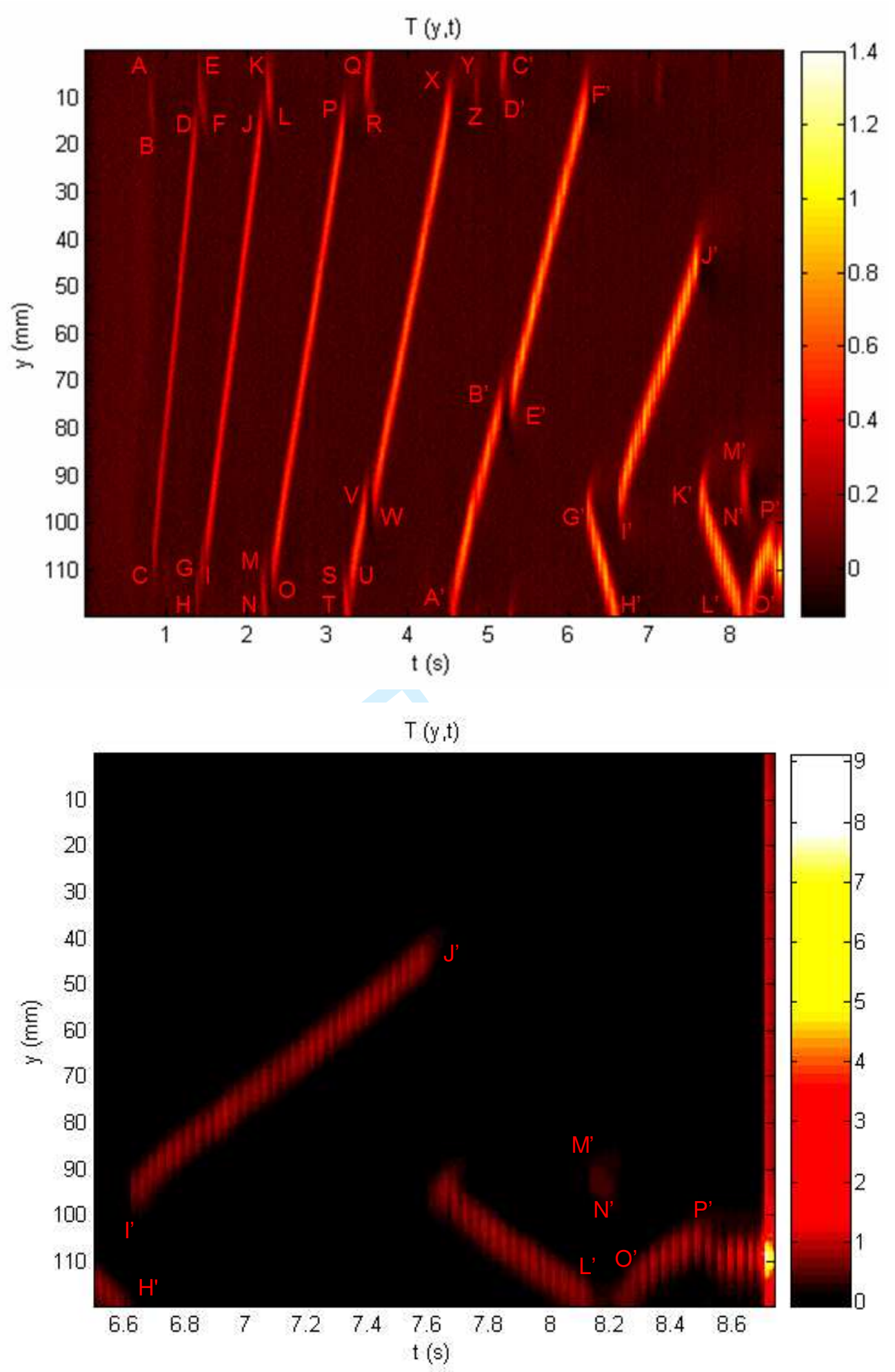

Fig 8: Temperature change measured along the centerline of the specimen for test T4. From the beginning of the test to $\mathrm{t}=8.7 \mathrm{~s}$ (top) and from $\mathrm{t}=6.5 \mathrm{~s}$ to failure (bottom). The last band stops, leading to localization and final failure of the specimen. Note the increase of temperature due to plastic dissipation (up to $9^{\circ} \mathrm{C}$ ). 
Effects of strain rate in the characteristics of PLC deformation bands for AA5083-H116 aluminium alloy
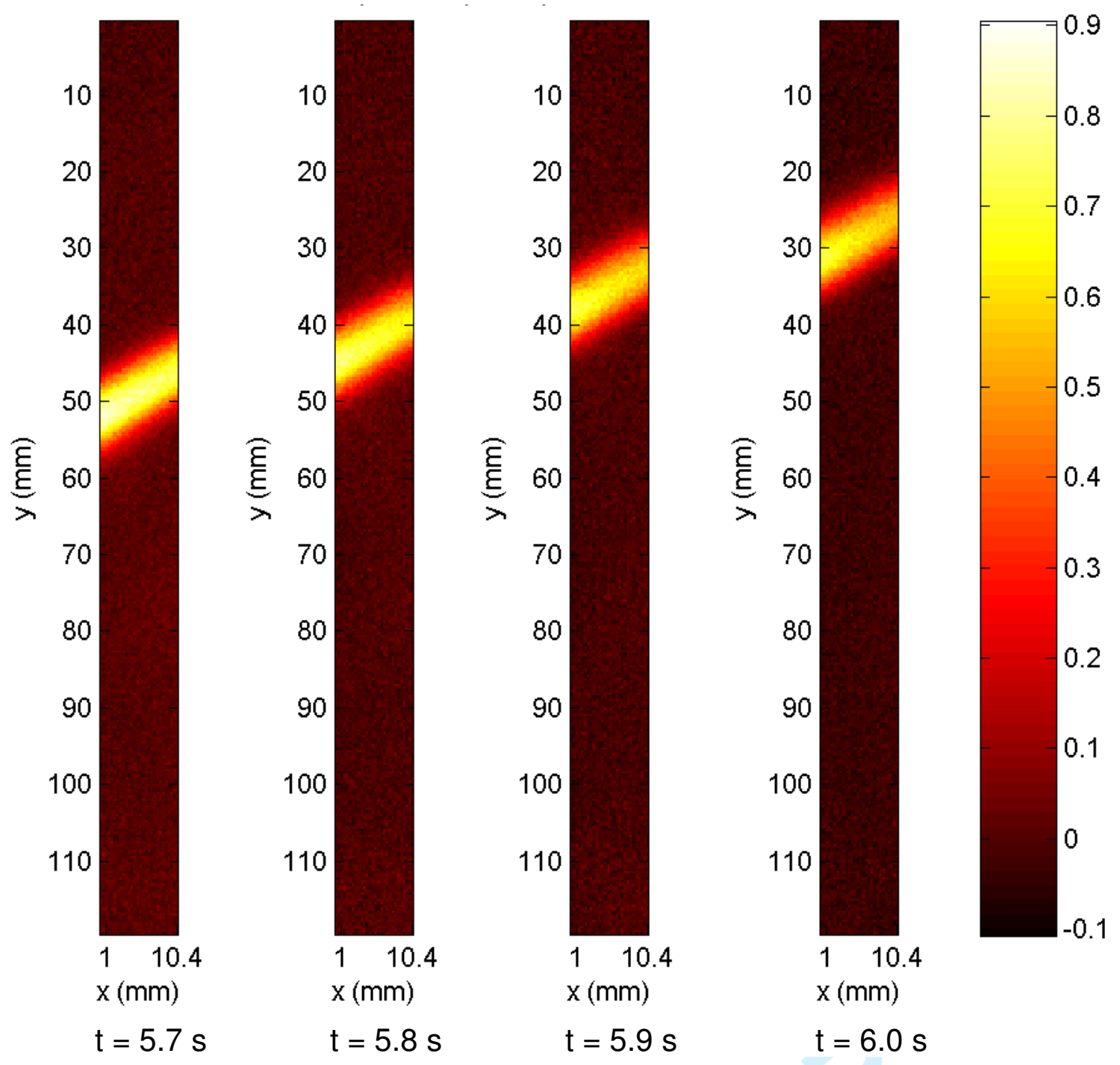

Fig 9: Sequence of four DIT images showing the propagation of a PLC deformation band during test T4. 
A. Benallal, T. Berstad, T. Børvik, O.S. Hopperstad \& R. Nogueira de Codes
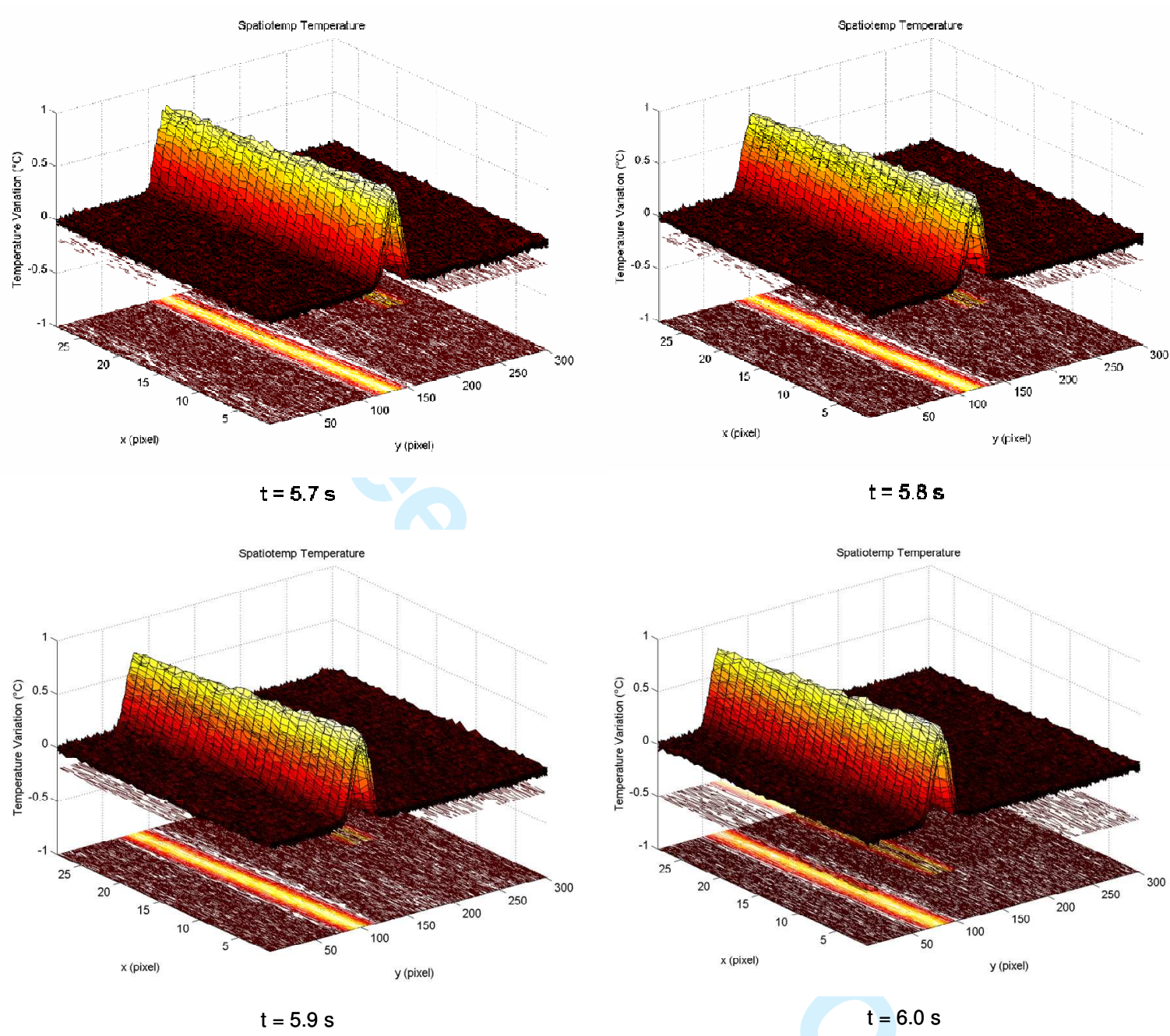

$t=5.9 s$

Fig 10: Three-dimensional view of the deformation band shown in Fig 9: Temperature distributions at different time locations. 
Effects of strain rate in the characteristics of PLC deformation bands for AA5083-H116 aluminium alloy

2

3

4

5

6

7

8

9

10

11

12

13

14

15

16

17

18

19

20

21

22

23

24

25

26

27

28

29

30

31

32

33

34

35

36

37

38

39

40

41

42

43

44

45

46

47

48

49

50

51

52

53

54

55

56

57

58

59

60
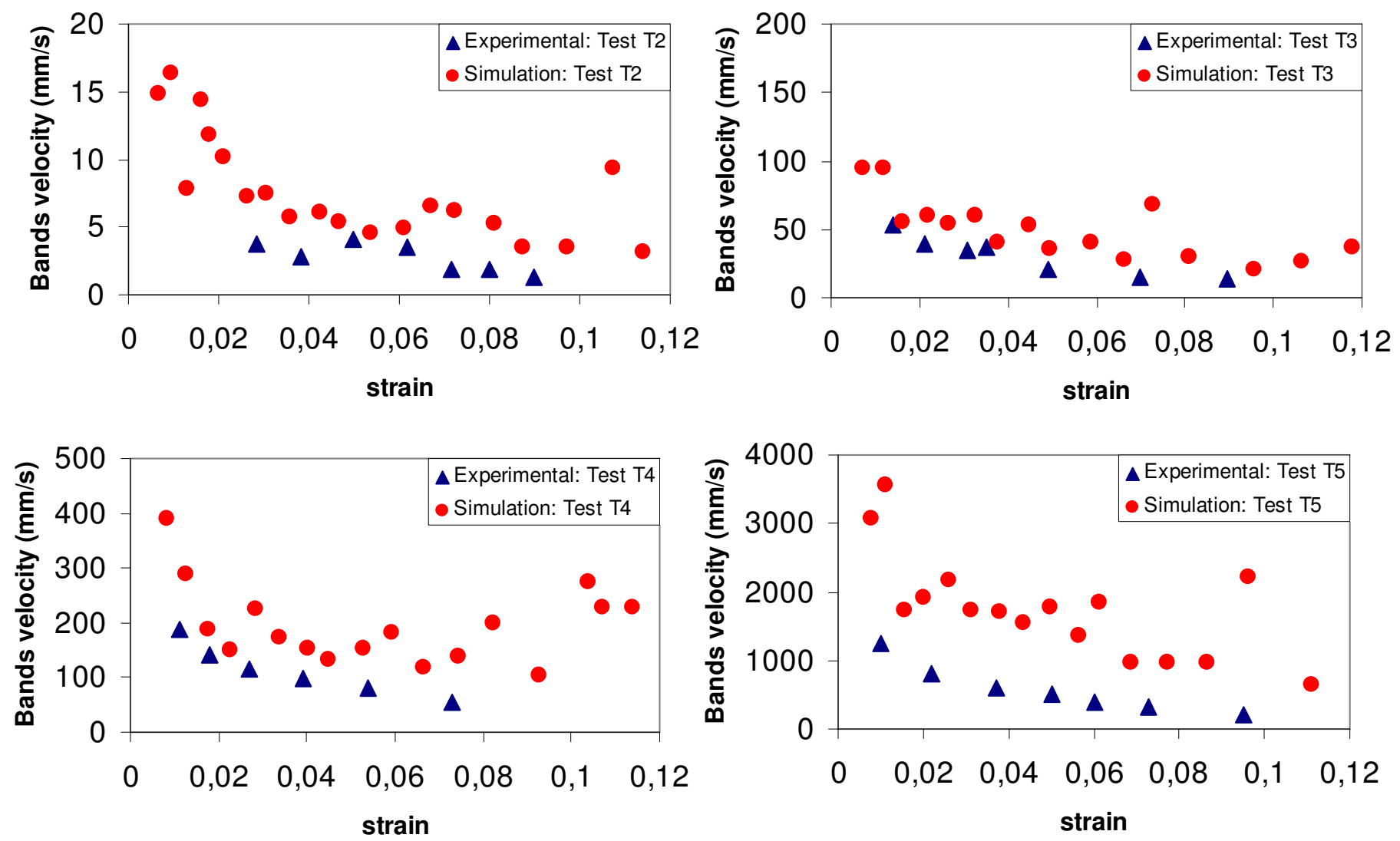

Fig 11: Band velocities versus strain for tests T2, T3, T4 and T5. Only Type C bands (static) were observed in test T1. 
A. Benallal, T. Berstad, T. Børvik, O.S. Hopperstad \& R. Nogueira de Codes
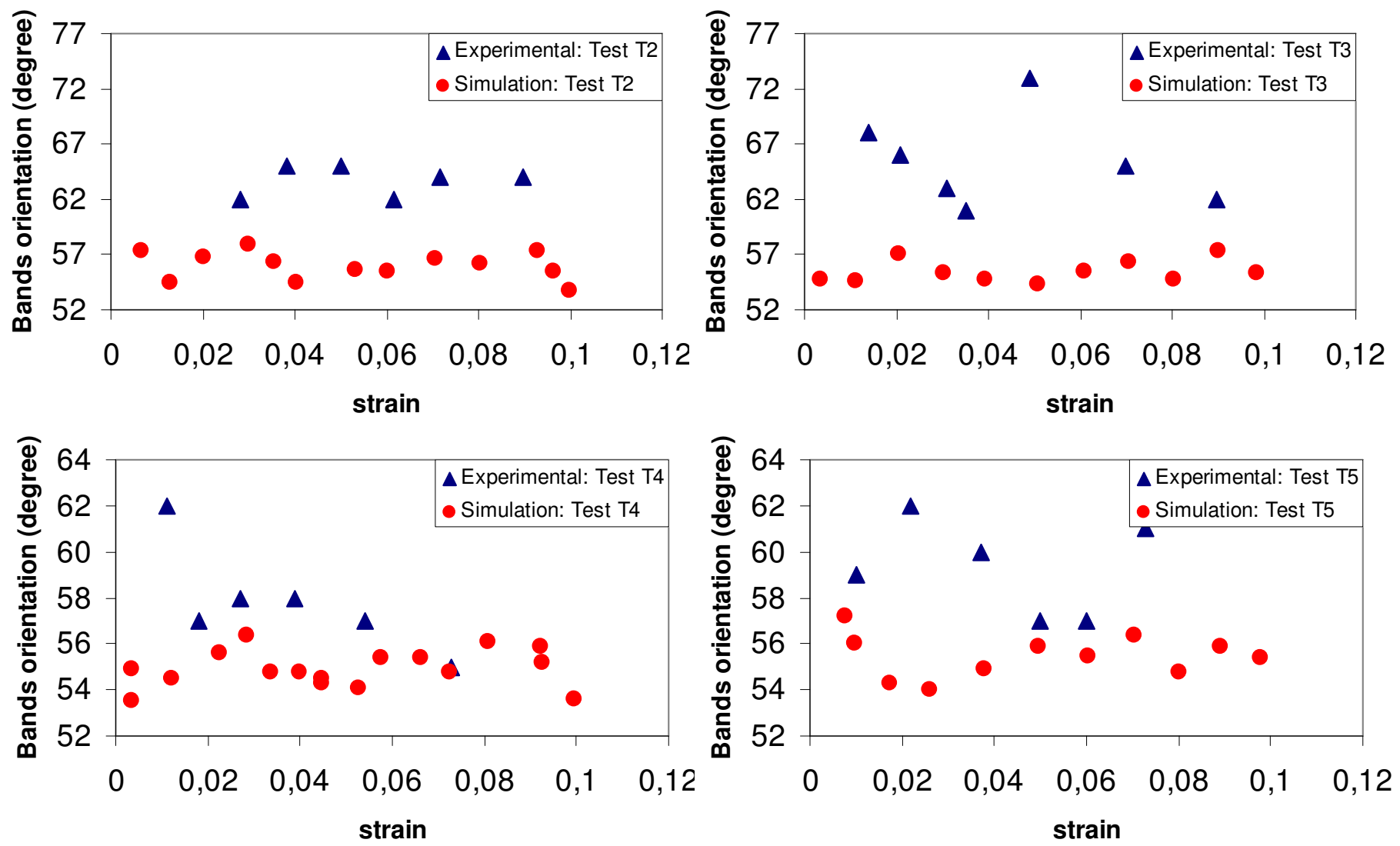

Fig 12: Band orientations versus strain for tests T2, T3, T4 and T5. 
Effects of strain rate in the characteristics of PLC deformation bands for AA5083-H116 aluminium alloy

1

2

3

4

5

6

7

8

9

10

11

12

13

14

15

16

17

18

19

20

21

22

23

24

25

26

27

28

29

30

31

32

33

34

35

36

37

38

39

40

41

42

43

44

45

46

47

48

49

50

51

52

53

54

55

56

57

58

59

60
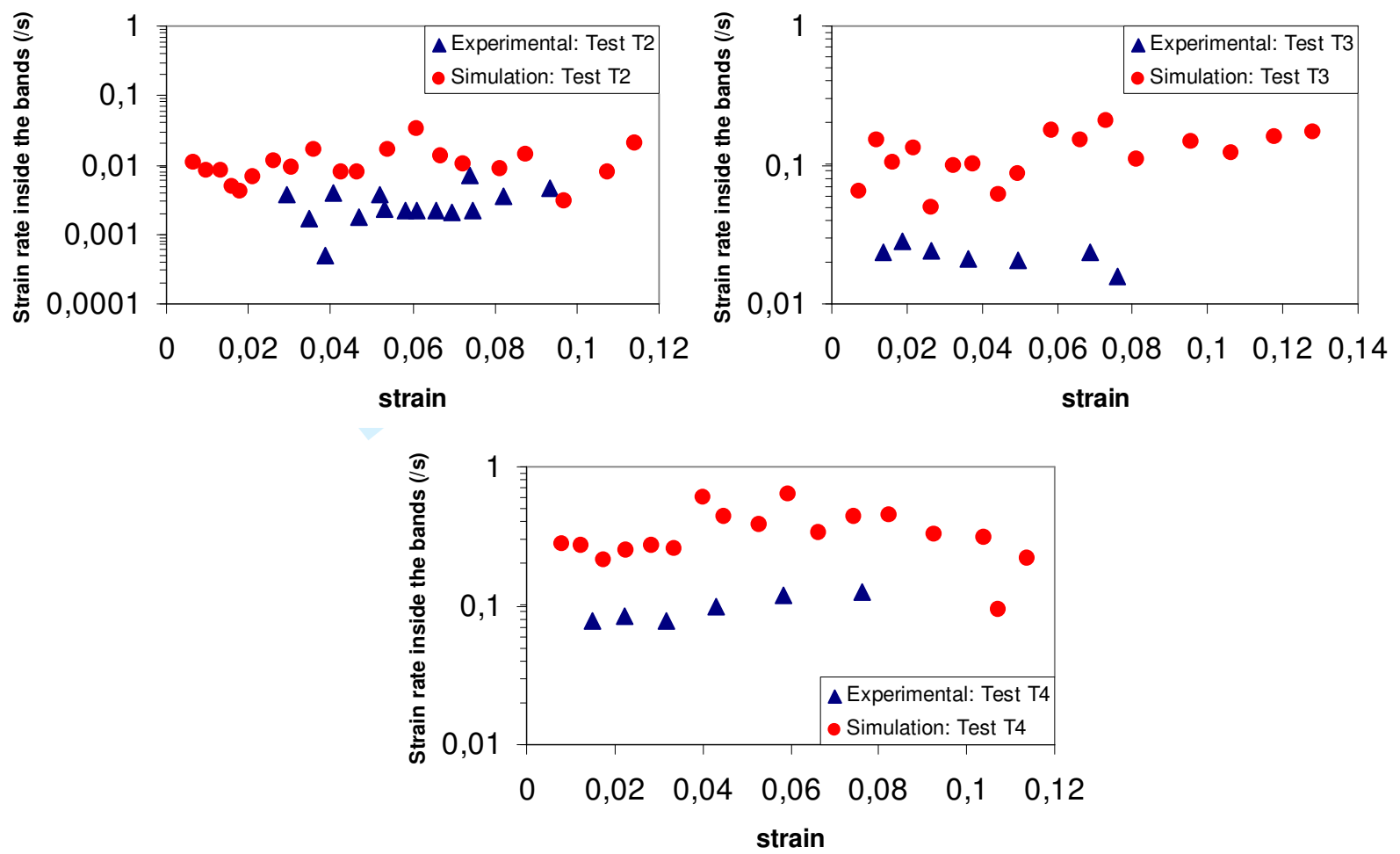

Fig 13: Strain rate inside the bands versus strain for tests T2, T3 and T4.

http://mc.manuscriptcentral.com/pm-pml 
A. Benallal, T. Berstad, T. Børvik, O.S. Hopperstad \& R. Nogueira de Codes
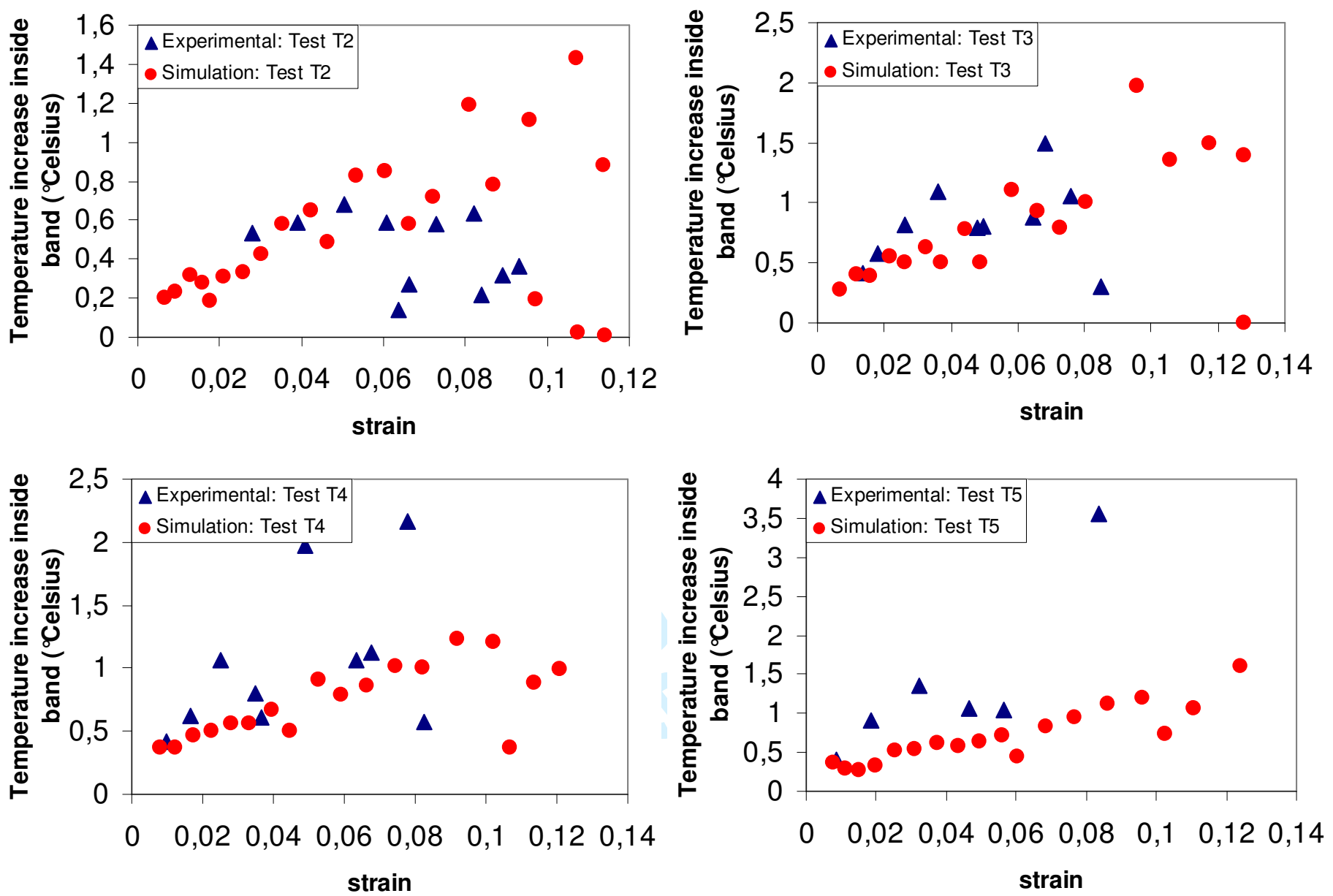

Fig 14: Temperature change inside the bands versus strain for tests T2, T3, T4 and T5. 

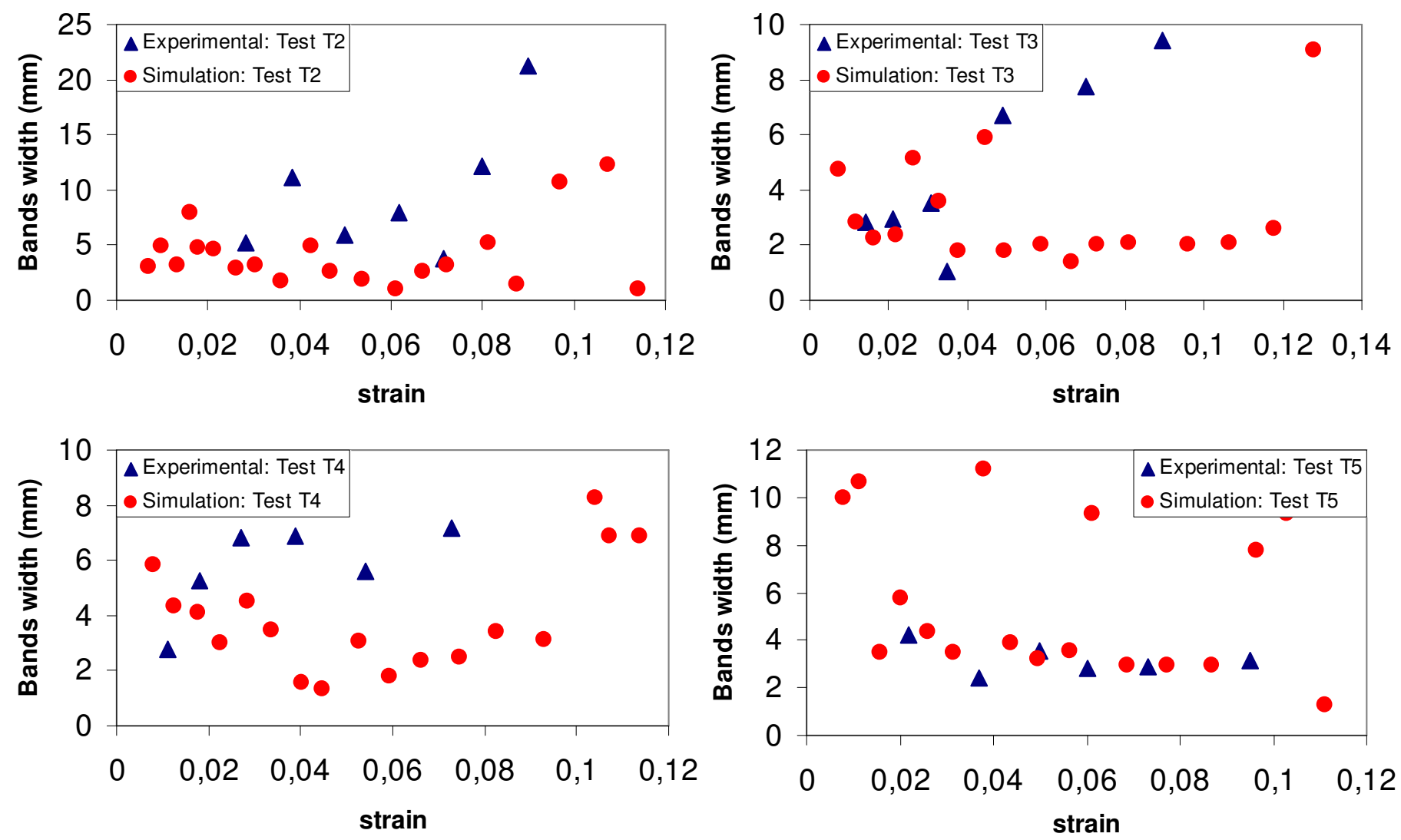

Fig 15: Band widths versus strain for tests T2, T3, T4 and T5. 
A. Benallal, T. Berstad, T. Børvik, O.S. Hopperstad \& R. Nogueira de Codes
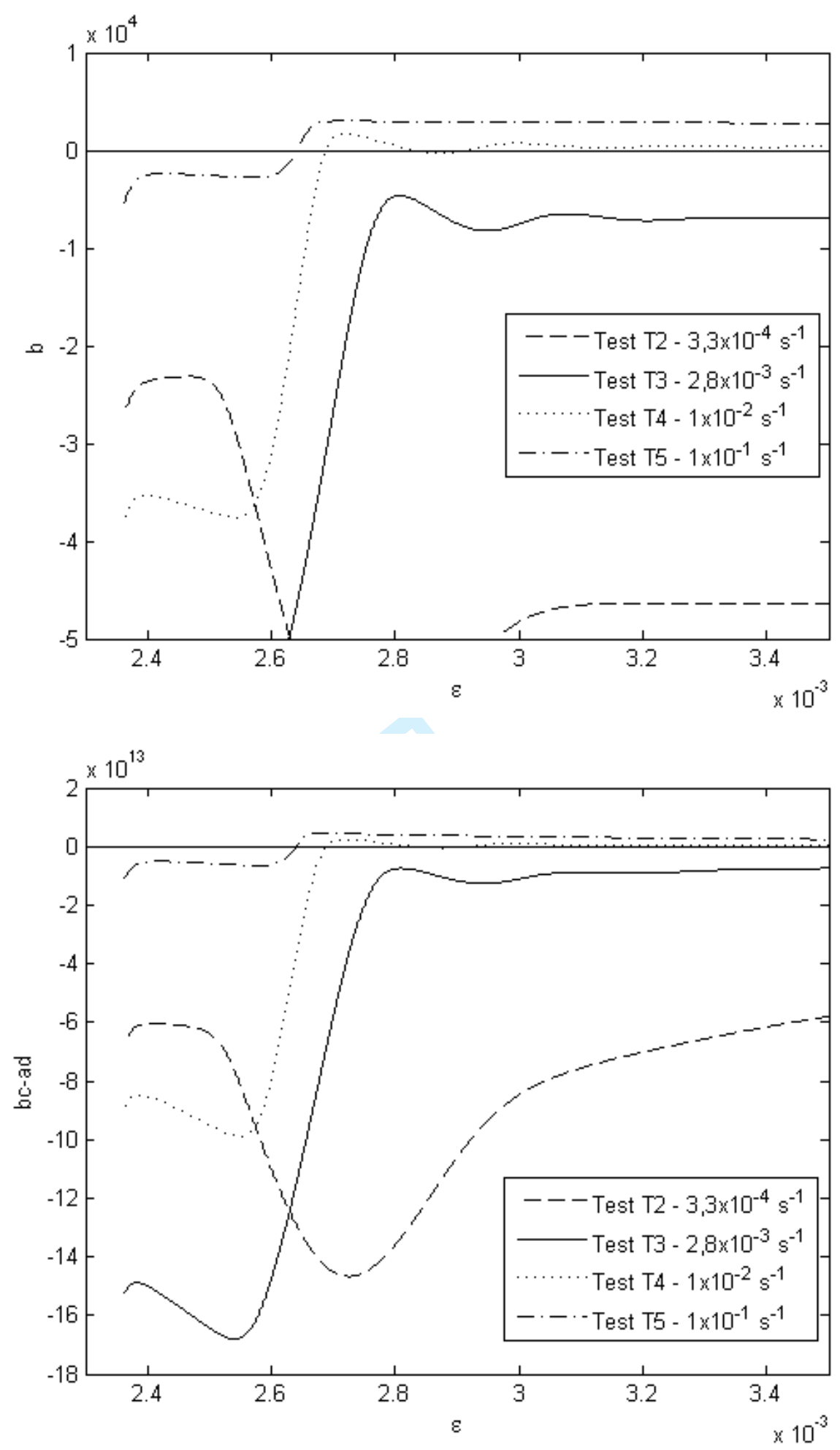

Fig 16: Evolution of coefficient $b$ and $b c-a d$ during tension tests T2, T3, T4 and T5. 
Fig 17: Angle $\theta_{c}$ of the cone containing all the admissible critical orientations versus critical growth rate $\bar{\eta}_{c}$ obtained by the perturbation approach for the tension test (Equation (15) with $N_{2}=-1 / \sqrt{6}$ ). 
A. Benallal, T. Berstad, T. Børvik, O.S. Hopperstad \& R. Nogueira de Codes

Fig 18: Finite element model used in the numerical simulations. 


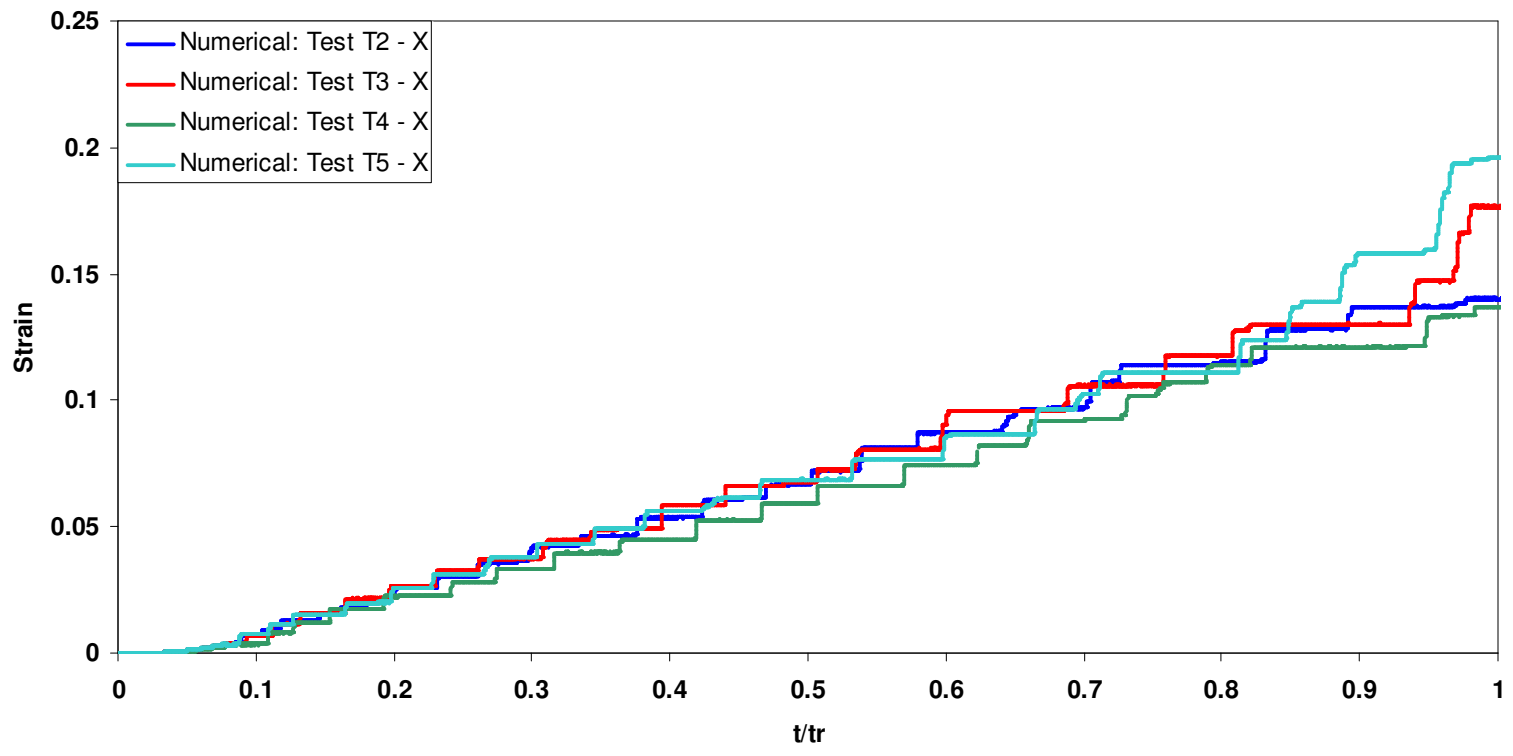

Fig 19: Force-displacement curves plotted to $10 \mathrm{~mm}$ displacement, i.e. before necking, from all simulations (top) and strain history at location X for tests T2 to T5 (bottom), where the time axis has been normalized with the time to necking for each test. 
A. Benallal, T. Berstad, T. Børvik, O.S. Hopperstad \& R. Nogueira de Codes

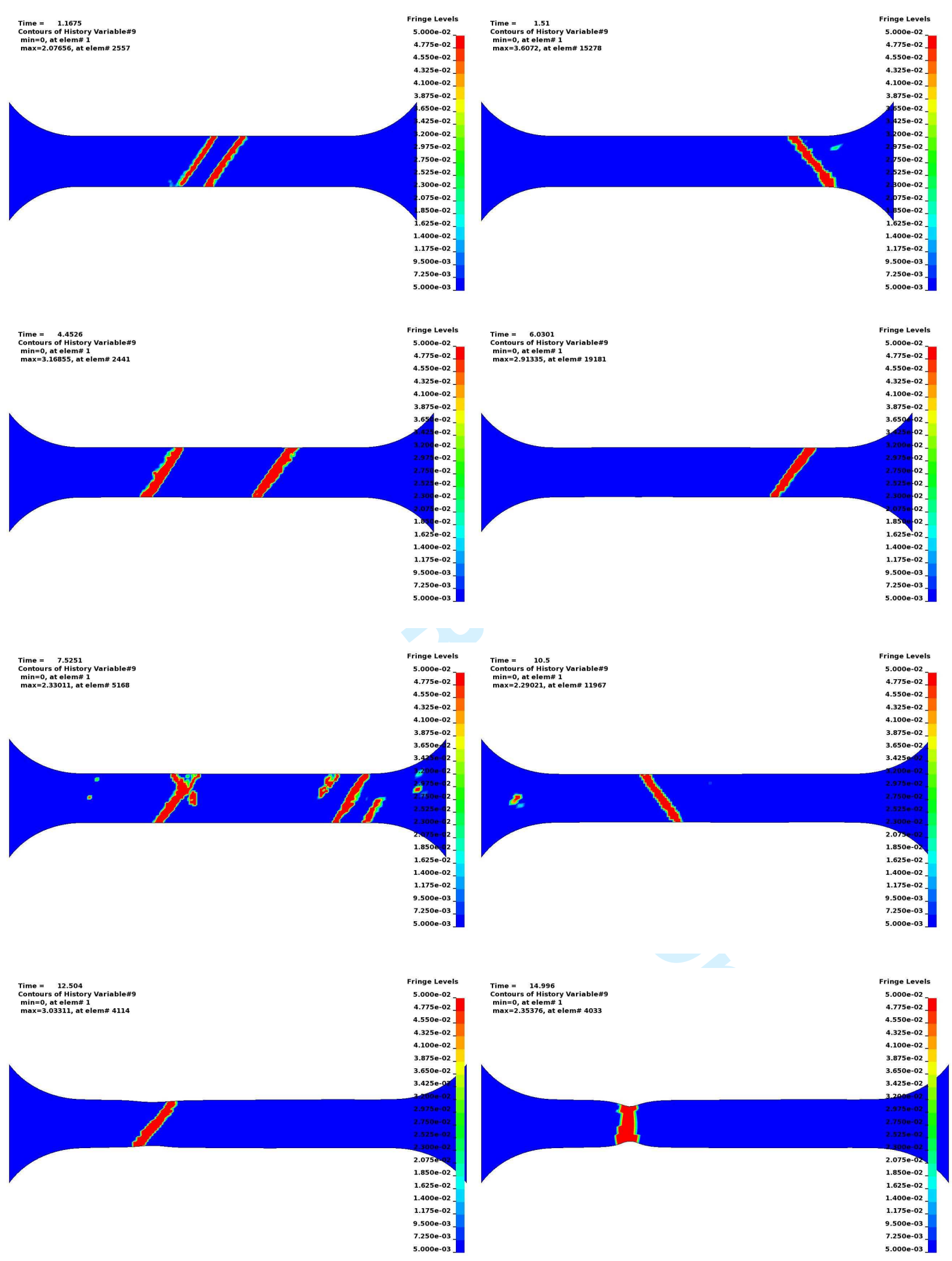

Fig 20: Some strain-rate fringe plots of band propagation in test $\mathrm{T} 4(\mathrm{v}=1.2 \mathrm{~mm} / \mathrm{s})$. 
Effects of strain rate in the characteristics of PLC deformation bands for AA5083-H116 aluminium alloy

Table 1: Summary of all the tests carried in the present study.

\begin{tabular}{|c|c|c|c|}
\hline Test & $\begin{array}{c}\text { Cross head velocity } \\
(\mathrm{mm} / \mathrm{s})\end{array}$ & $\begin{array}{c}\text { Nominal strain rate } \\
\left(\mathrm{s}^{-1}\right)\end{array}$ & $\begin{array}{c}\text { Gage length } \\
(\mathrm{mm})\end{array}$ \\
\hline $\mathrm{T} 1$ & 0.0035 & $2.92 \times 10^{-5}$ & 120 \\
\hline $\mathrm{T} 2$ & 0.04 & $3.33 \times 10^{-4}$ & 120 \\
\hline $\mathrm{T} 3$ & 0.34 & $2.83 \times 10^{-3}$ & 120 \\
\hline $\mathrm{T} 4$ & 1.2 & $1 \times 10^{-2}$ & 120 \\
\hline T5 & 12 & $1 \times 10^{-1}$ & 120 \\
\hline
\end{tabular}

Table 2: DIC and DIT data.

\begin{tabular}{|c|c|c|c|c|c|c|}
\hline \multirow{2}{*}{ Tests } & \multicolumn{3}{|c|}{ CCD Camera } & \multicolumn{3}{c|}{ Infrared Camera } \\
\cline { 2 - 7 } & $\begin{array}{c}\text { Image size } \\
\text { (pixels) }\end{array}$ & $\begin{array}{c}\text { Acquisition } \\
\text { shutter } \\
\text { (frames } / \mathrm{s})\end{array}$ & $\begin{array}{c}\text { Conversion } \\
\text { factor } \\
(\mathrm{mm} / \text { pixel) }\end{array}$ & $\begin{array}{c}\text { Image size } \\
\text { (pixels) }\end{array}$ & $\begin{array}{c}\text { Acquisition } \\
\text { shutter } \\
\text { (frames /s) }\end{array}$ & $\begin{array}{c}\text { Conversion } \\
\text { factor } \\
(\mathrm{mm} / \text { pixel })\end{array}$ \\
\hline T1 & $128 \times 640$ & 50 & 0.1875 & $45 \times 315$ & 150 & 0.38095 \\
\hline T2 & $128 \times 512$ & 50 & 0.23438 & $35 \times 302$ & 25 & 0.39735 \\
\hline T3 & $128 \times 512$ & 125 & 0.23438 & $24 \times 306$ & 150 & 0.39216 \\
\hline T4 & $128 \times 512$ & 125 & 0.23438 & $28 \times 302$ & 150 & 0.38735 \\
\hline T5 & $128 \times 512$ & 125 & 0.23438 & $45 \times 317$ & 150 & 0.37855 \\
\hline
\end{tabular}

Table 3: Parameters of the extended Voce rule.

\begin{tabular}{|c|c|c|c|c|}
\hline$\sigma_{0}[\mathrm{MPa}]$ & $Q_{1}[\mathrm{MPa}]$ & $C_{1}$ & $Q_{2}[\mathrm{MPa}]$ & $C_{2}$ \\
\hline 165.4 & 8.8 & 1385.8 & 219.3 & 15.9 \\
\hline
\end{tabular}


A. Benallal, T. Berstad, T. Børvik, O.S. Hopperstad \& R. Nogueira de Codes

Table 4: Parameters of the McCormick constitutive relation.

\begin{tabular}{|c|c|c|c|c|c|}
\hline$S[\mathrm{MPa}]$ & $\dot{p}_{0}[1 / \mathrm{s}]$ & $H$ & $\Omega$ & $t_{d}[\mathrm{~s}]$ & $\alpha$ \\
\hline 2.23 & $1.0 \mathrm{E}-8$ & 27.9 & $1.0 \mathrm{E}-4$ & 0.02 & 0.336 \\
\hline
\end{tabular}

Table 5: Other parameters for aluminium alloys.

\begin{tabular}{|c|c|c|c|c|}
\hline$\rho\left[\mathrm{kg} / \mathrm{m}^{3}\right]$ & $C_{p}[\mathrm{~J} / \mathrm{kgK}]$ & $\chi$ & $E(\mathrm{MPa})$ & $v$ \\
\hline 2700 & 910 & 0.9 & 70000 & 0.31 \\
\hline
\end{tabular}

